\title{
The Use of Theory and Methods of Behavioural Economics in the Process of Making Financial Decisions
}

\author{
Maria Rozina*
}

\author{
Master of Economics \\ International Finance Faculty, \\ Department of World Economy and World Finance, \\ Financial University, Moscow, Russia
}

\section{Abstract}

This article discusses some issues connected with studies of the behavioural factors when making financial decisions. Therefore, it is possible to take into account factors that are inexplicable in traditional models. The main goal of our research was verification of the hypothesis market participants make financial decisions based on their experiences, intuition, stereotypes, illusions, emotions and not only on the criterion of financial gain and rational assumptions. After all, such diverse behaviour en masse influences the financial system as a whole. The practical significance of reported here study is the identification of errors in the application of classical economic theory and the possibilities of their further elimination. An effective behavioural model to avoid negative consequences is the primary tool in making financial decisions. In the first part, the author analyses the theoretical basis of her study. The second part examines the main problems associated with classical economic theory and presents the main mistakes in making financial decisions. Particular attention the author paid to the study of the behaviour of investors and managers. The third part described the research of behavioural mechanisms in making financial decisions with specific examples and implementation of the use of mathematical models.

Keywords: behavioural economics; decision-making; investor; homo economicus; rational decisions; irrationality JEL Classification: D03, D53, G02, G11, G14

\section{Introduction}

The performance of any financial and economic entity, its long-term success and a stable position on the market are primarily determined by the effectiveness of financial policies, the quality and adequacy of financial decisions. The classical economic theories assume that the process of making financial decisions is an absolutely rational one. However, classical economic theories do not take into account the fact that there are humans at the centre of any financial processes.

Thus, the main problem is that economists use models that replace the notion of "ordinary person" with "rational person". In contrast to the ideal "rational person”, “ordinary people” make mistakes and take wrong decisions. Therefore, economic models and theories give erroneous forecasts and lead to negative consequences.

The general assumption made under the particular research question is that people making decisions, including top management, do not always act rationally. In most cases, people make decisions based on experience or intuition. The classical theory does not take into account these factors. Thus, making such decisions is inefficient and does not lead to the desired financial results. We should also take into consideration the possibility of irrational behaviour. Therefore, in our

\footnotetext{
* Scientific supervisor: Tatyana Goroshnikova, PhD in Technical Sciences, International Finance Faculty, Department of World Economy and World Finance, Financial University, Moscow, Russia.
} 
research, we used methods of analysis and evaluation of behavioural factors determining the financial decision-making process.

Consequently, we want to check how people make rational financial decisions in the modern world. The behavioural finance implies an approach in which not all participants of the market are entirely rational. The behavioural theory rejects the idea of individual rationality. Analysing and systematising this knowledge lead to optimisation the process of making financial decisions and reducing negative consequences.

Moreover, models based on the classical economic theory believe that a person makes decisions oriented towards the possible optimal result. Furthermore, they assumed that a "rational person" makes this or that choice impartially - that he/she does not overestimate his capabilities. However, the reality is not so perfect: an economist (a man by nature) does not act impartially in making decisions.

The Theory of Moral Sentiments is a 1759 book written by Adam Smith, a central figure of the classical political economy. This book is about human feelings, their influence on relationships between people, about attitudes towards wealth. Thus, one of the founders of economic theory as a science openly recognised the significance of human nature.

Nevertheless, the classical model of economic behaviour based on the concept of "rational man" exists and develops over the years. For a long time, adherents of the classical theory responded to criticism with the approach which ignored empirical inferences. Over time, such observations have generated the new direction of researches. There appeared scientific papers describing improper decisions and their consequences in the financial sphere such as managing retirement savings, choosing a mortgage loan, investing in the stock market, corporate management of companies, "booms", "bubbles" and market crashes leading to financial crises. The behavioural approach to economics and finance emerged as a renewed approach to economic research that recognises and takes into account the human factor.

In the literature, the question of corporate behavioural finance and its impact on financial decision-making is well examined and proved by various studies. Behavioural Finance: Psychology, Decision-Making, and Markets (2009) is a study written by Lucy Ackert and Richard Deaves. They focused on understanding how human behaviour influences the decisions of individual and professional investors, markets and managers.

Misbehaving: The Making of Behavioural Economics (2016) by Richard Thaler, who is the Nobel Prize winner in economics in 2017 for his contribution to the field of behavioural economics. The author manages to focus on the fact that a person is not a robot who thinks solely based on laws and theories. The study presents a large number of real-life examples. Moreover, Thaler tested his theories and conclusions in real business and solved bankruptcy problems.

Beyond Greed and Fear: Understanding Behavioural Finance and the Psychology of Investing (2002) is the study of Hersh Shefrin is the study of how psychology impacts finance. The author identified three areas of difference between behavioural finance and traditional knowledge of finance. While based on the conventional financial doctrine, subjects of financial relations use mathematical and statistical methods and make the right decisions, in behavioural finance, subjects can use heuristic methods of knowledge processing and, as a result, make wrong decisions.

\section{Theoretical Aspects of Behavioural Economics and Finance}

\subsection{Factors contributing to the emergence and development of behavioural finance}

The financial concepts of the 1940s did not allow for the existence of a capital market. Each Financial Contract is unique, and comparison with ordinary market rates is meaningless. In the 1950s, the stock market was not such a large capital supplier as the companies themselves. Economists at the time did not consider the stock market a suitable subject for serious research. And until the 1960s, stock prices were studied mainly by statistics (Chuvakhin, 1960). In the 1950s, the business administration doctrine focused on the relationship between finance and accounting. Administrators of that time believed that financial and investment transactions are reflected primarily in the balance of assets and liabilities. Investors were mostly interested in the return on equity (ROE) and the return on investment (ROI). Nowadays, managers remind about maximising ROE as an all-consuming business goal. The main disadvantage of this approach is that the endless details hide the true goals of the company. 
Driven by new developments and mechanisms in the financial market, a scientific revolution took place in the second half of the 1950s - the first half of the 1960s. A massive increase in researches on the stock market began. Neoclassical finances started to replace 'old' finances since the latter could not answer essential questions:

The law of the market is the law of a single price. Then how is it possible that different financing options can be offered to the same firm at different prices in the same market?

Why are accounting, financial statements and coefficient analysis so important, although newspaper columns about stock prices are more important for shareholders?

What can an unrealised profit say about a firm if investors are only interested in the yield generated by the added value and dividends relative to the market value?

Therefore, a new finance paradigm should have appeared and emerged. Since the capital market is perfect, it is the only appraiser of any financial event. This statement is a paradigm of neoclassical finance since the neoclassical economy puts the perfect market at the centre of all its theories. The approach incarnated in neoclassical finances was revolutionary. There appeared new answers to old questions.

Then the neoclassical theory of finance began to form. Neoclassical economics had a strong influence on financial science. It assumes the existence of a capital market perfect in any sense. Modigliani and Miller, who promoted market thinking, formed a hypothesis that is still not refuted in our time. They realised that the price reflects the attractiveness of the product for the entire population in a market economy. It means that the market value of the firm (market capitalisation) is the price of this common stock multiplied by their number in circulation in the market. Thus, maximising capitalisation is the best that managers can do for shareholders. It was a revolutionary discovery. Neither ROE nor longterm benefits are already key variables. The main thing is the added value determined by positive cash flow. Accounting profit only allows you to specify the forecast of this stream.

Shleifer called the theory of an efficient capital market the "consequence of equilibrium in competitive markets with fully rational investors" (Shleifer, 2018, p. 369). The theory of an effective market is based on three main ideas:
1) Rational investors evaluate stocks in a rational way.

2) Irrational investors may enter into random transactions that level each other and do not affect stock prices. Such investors are called noise-traders and transactions - noise.

3) Rational investors liquidate the deviations created by transactions of irrational investors of stock prices. The process of eliminating anomalies by investors is called arbitration.

On this basis, it is argued that the stock market is extremely effective in reflecting information about individual companies, industries and the entire economy. News spreads quickly, equally accessible to all market participants and instantly reflected in prices. From here, you can make two conclusions:

The arrival on the market of new information about the shares of a particular company causes an immediate correction of the fundamental value, and with it the price of shares;

Prices will not change until new information on fundamental value arrives on the market.

In the theory of rational expectations, rational expectations are identical to the forecast, which absorbed all the available information and is therefore optimal. The results of the forecast differ randomly, but not systematically, from the results of market equilibrium. Accordingly, rational expectations do not differ regularly or predictably from equilibrium results. Predicting the future, people do not make systematic mistakes. Forecast errors are random.

Thus, all investors, small and large, should control risk by of income. Everybody should have a standard portfolio of assets called a market portfolio. Striving for the exact coincidence of their portfolios with the real market portfolio and realising the passive strategy of portfolio management, they will act rationally. Thus, even uninformed people can buy and sell at any time, without fear that they will be deceived by more informed market participants like insiders. An effective market protects the uninformed and therefore attracts the "masses". It is a democratic market.

At the same time, market participants should be warned if the market is inefficient: "The current price may not reflect the true value, which is known only to a few informed participants." However, it is very doubtful that there would be a significant number of those who want to take part in that type of market. In an inefficient market, the public should not engage in direct transactions but 
should delegate to experts the right to trade at their own expense. But then access to the market is difficult, and market activity will be the privilege of a few insiders and professionals. The market in such conditions will cease to exist as a key institution of modern society.

Let's try to consider a person, not a market, as the centre of the financial and economic world. People control the economy and finance. The rational and irrational components of our choice are transferred to the economy and finance and influence the process of making financial and economic decisions. The behavioural approach examines the influence of social, cognitive and emotional factors on the economic and financial decisions of individuals and institutions and the implications of this influence on market variables (prices, profits, allocation of resources).

One of the most important trends in modern science is a change in the forms of rationality as a fundamental postulate of neoclassical theory. The concept of rationality and irrationality, understanding their influence on the forms of economic and financial activity, are changing radically. Scientists, based on the results of psychological research in the field of decision making, prove that people do not always behave rationally, even in their interests because of such behavioural features as self-control problems, inability to distinguish between profit and loss, difficulties in choosing between large sets of parameters, complex products, asymmetry in the perception of gains and losses, etc. In this regard, many of the results of behavioural research are relevant, and more and more research on the subject appears.

In a conventional, classical economy, the assumption of rationality means that in everyday life, people compare all the alternatives that appear to each other (on any subject), and then choose the best one.

Within the framework of behavioural economics, the methodological approach is initially associated with the criticism of rationality in human behaviour, whose abilities are limited due to inaccessibility of complete information and susceptibility to habits and emotions. Researchers emphasise two crucial aspects of economic behaviour:

Non-rationality is a temporary state of the subject.

Irrationality has systematic patterns that can be measured.
Considering the rational and irrational in human behaviour, B. Hert writes: "Irrationality is a more fundamental normative concept than rationality. To call an act irrational is to declare that it should not be done; if the act is qualified as rational, then it still does not follow that it must be performed, since two (or more) rational alternatives are possible. Undoubtedly, each person, in any case, should act rationally, but this only implies that no one should ever perform irrational actions, and not at all that any rational perspective should be realised. If I have doubts as to whether this act is rational or irrational, I would rather call it rational. At the same time, it is quite possible that one would consider rational actions as such the other people would prefer to call irrational. This discrepancy, generally speaking, is unimportant, unless one decides that any concession to others is irrational. The main thing for me is not to include such a deed into the class of the irrational that someone else considers rational" (Chernyavsky, 2014, p. 22).

Causes of irrational behaviour:

The juxtaposition of the present and the future. People are not predisposed to perceive reality through the prism of a long-term perspective.

Abstraction of money as a concept. One of the most powerful psychological barriers of a person is the difficulty of perceiving the alternative cost of money.

Behavioural economics points to regular failures in rational behaviour, systematic errors of economic participants when making decisions, and in this regard studies such phenomena as:

"Herd behaviour",

"Contamination by ideas",

"Degraded thinking",

"Collective euphoria",

"Collective fear".

One of the main areas of research in behavioural economics is heuristics. Heuristics is an algorithm for solving the problem. The basic idea is that human time and mental abilities are limited. As a result, a person uses a simple (heuristics) method of solving a problem to make a particular judgment or make a decision. Imagine the question of how common the name Wang is. All answer that the name is rare, except for those who live in China, where the name Wang is found very often. Considering that China is the world's populous country, on a global scale, this name is quite common. To decide how common a particular phenomenon 
is, people usually ask themselves how often they have met. However, this method does not work in cases where the actual frequency of repetition of an event does not correspond to the one that can be observed in its daily life (as is the case with the name Wang).

Frames are another key focus of research. The frame is an abstract concept, implying "the analysis of various integrity (social, cultural) and then the assembly of structures as a set of interacting elements". Traditionally, human actions are considered as depending on the situation in which they are produced, and on the personal characteristics and qualities of the person who performs them. The concept of a frame introduces one more - the semantic angle of their consideration, speaking as a framework of social representations, within the framework of which a person determines for himself the situation in which he acts.

The third direction of behavioural economic development is market inefficiency. These are decision making errors in the market that lead to various market anomalies, including incorrect pricing, inefficient allocation of resources.

Three closely interrelated components are, as a rule, selected by scientists:

1) The decision of a person is usually preceded by perception, understanding, understanding of the situation and oneself in it, that is, cognitive components;

2) Subjective attitude, coloured feelings, that are emotional components;

3) The action or, conversely, its containment, that is, effectively dynamic components.

The main problems of economic theory solved in the framework of behavioural economics and finance:

An assumption about the axiom of independence for the theory of expected utility that does not meet reality conditions of the environment in which it is now located;

The premise of the homogeneity of all goods (the effect of the initial stock: the agent appreciates the benefits that he had initially been, more than those that he can acquire as a result of the exchange; thus, non-standard situations arise around the point of the initial stock);

The imperfection of human memory and computational abilities, which is fraught with failure to achieve the best possible result;
The problem of discounting (in reality, agents are more focused on short-term interests than on planning the far horizon).

The central question to behavioural finance research is "Why do market participants systematically make mistakes?” These errors affect prices and profits, which leads to market inefficiency. Besides, behavioural finance looks at how other participants in market relations are trying to gain from inefficiency. The main reasons for inefficiency are, firstly, the excessive and insufficient reaction to information that sets market trends (in exceptional cases, the economic bubble and the market crash) - secondly, limited attention of investors, excessive self-confidence, excessive optimism, herd instinct and noise trading. Technical analysts view behavioural economics and behavioural finance as the basis of technical analysis. Thirdly, the critical issue is the asymmetry between the decision to accumulate and save resources, known as the "bird in hand" paradox, and the fear of loss, unwillingness to part with valuable property. The trap of irrecoverable costs manifests itself in such an investor's behaviour as reluctance to sell stocks, provided that this nominally results in a loss. It can also explain why housing prices rarely and slowly fall to the level of market equilibrium in a period of low demand. The experimental financial theory uses an experimental method, in which an artificial market is created with the help of modelling software to study the decision-making process of people and their behaviour in financial markets.

Nobel laureate Herbert Simon took a big part in the devaluation of the classical theory of rational choice. This scientist, relying on the work of Modigliani and Miller on the theory of the company, set himself the task "to replace the global rationality of economic man with a kind of rational behaviour that is compatible with the access to information and the computational capacities that are actually possessed by organisms, including man, in the kinds of environments in which such organisms exist (...) and propose definitions of 'rational choice' to become a real decision-making processes...” (Simon, 1955, p. 99).

Applying the tools of the theory of rational choice with reality, Simon concluded that people make not optimal, but convenient decisions. That is, they rationally satisfy, rather than rationally optimise their needs. Behavioural economics, built on this idea, rejects the role of limited optimisation in the decision-making process. Limited rationality has 
become the central theme of behavioural economics and finance.

In the 1990s, modern finances have undergone extensive and sophisticated empirical testing. The results are disappointing for the profession of a standard economist. The nature of the criticism of the efficient market theory can be judged by the words of Jonathan Berk: "The hypothesis of an efficient market (...) was an important part of the modern financial economy and remained an influential intuition, but as a formal construct, it experienced a period of its usefulness for the financial economy. I show that most forms of a hypothesis are not testable, and in tested forms, a hypothesis is easily refuted by data. The idea of unpredictable profitability is erroneous and holds back research on the financial economy... There is growing evidence that some market participants receive substantial economic rent from trade. The time has come to revise the paradigm and recognise that profitability is predictable ...” (Berk, Stanton, \& Zechner, 2008).

Economists wondered why models suddenly falter, why people do not behave in the way prescribed by the theory of rationality, which suggests that the market rate of an asset falls with its investment value. However, market prices depend on the opinion of the public, which, as we found out, is not always logical. Financial markets are too volatile because they react to a variety of news. It is how Keynes hypothesis appeared about excessive volatility.

The 1980s became a period of critical academic discussions about the viability of efficient market models in the light of econometric studies of price properties, revenues and dividends. Mainly actively discussed was the issue of excessive stock price volatility concerning the forecast issued by these models. In the theory of rational economics, behavioural assumptions were almost not considered.

The anomalies discovered in the course of testing the theory of rationality at worst could be considered insignificant deviations from a fundamental truth. But excessive volatility posed a greater danger to the whole concept than, for example, calendar effects on the stock market. Empirical evidence in favour of excessive volatility suggests that prices change without any fundamental reason.

In the early 1980s, Schiller tested the Keynes hypothesis. He reasoned that if the stock price equals the expected present value of future dividends, as required by a rational economy, then it should not change as much as this value itself. Schiller's plan was a direct application of a simple statistical principle: a good prediction has less variance than the predicted variable.

Using data on the stock prices of American companies for 100 years, Schiller compared the variance of prices with the variance of discounted dividends (after removing the trend) and found what Keynes predicted: the standard deviation of prices (forecast) was five times greater than the standard deviation of discounted dividends. This result, terrible for a rational economy, was confirmed by more sophisticated tests that took into account the non-stationarity of prices and discounted dividends (West \& Shiller, 1991, p. 269).

These results inspired those who sought reasons for price volatility beyond a rational economy, particularly in behavioural finance. The collaboration of finance and other social sciences, known as behavioural finance, has greatly enhanced knowledge of financial markets. Reasoning about the achieved influence of behavioural finance, it is essential to apply the correct standards. Of course, one should not expect that these studies will open up a method for quickly and reliably extracting big money from the inefficiency of financial markets. However, the theory of an efficient market can be refuted since it can lead to a radical misinterpretation of such important events as large bubbles in the stock market. Thus, rationality is discredited, and many economists and financiers are moving away from the idea of "rational markets".

Previously, many economists have ignored ideas about a person's limited ability to solve complex problems. They were quite satisfied that the existing models were not accurate enough and that the forecasts built on these models contained errors. In the statistical models used by economists and financiers, this problem is solved by the fact that the "error" of calculations is included in the equation. So, classical economists argue that errors resulting from limited rationality can be ignored. The behavioural approach suggests that such errors are not accidental, studies and systematises them, creates new methods based on the knowledge gained and applies them in practice.

\subsection{The history and evolution of the behavioural economics and theory of finance}

Economic science gradually expands the levels of analysis of the theory and practice of the econom- 
ic and financial life of society. Under the influence of globalisation and informatisation of society in modern conditions, there is a complication, evolutionary expansion and the emergence of a new scientific direction of behavioural research, which means the synthesis of psychology, economics and finance, the interrelation of human psychology and the behaviour of market participants.

Studies of the role of a human in the economic and financial areas of activity required a more indepth analysis of the mental and cognitive aspects of human activity, the influence of these aspects on the algorithm for making financial decisions. The model of a rational economist, conveniently placed at formal economic structures, has ceased to be satisfied due to the apparent inconsistency with reality.

However, if the role of a human in shaping economic and financial relations (his psychology, preferences, mistakes, etc.) is so significant, if a person creates an economy, then the question arises: what place do objective laws occupy in the real economy, and therefore in its theoretical versions? That is, how can the behaviour of people in the economic and financial world based on predetermined exogenous circumstances be explained (predicted, foreseen)? Behavioural economics and finance in studies of recent years have shown that people's preferences are endogenous, while in the classical theory they were accepted as unchanged and externally given. It means that they are subject to change, more importantly, they can form, change "inside" the activities of people under the influence of various factors, also perceived by the behavioural model as endogenous. It became apparent that objective circumstances have given from the outside (defined by the classical paradigm as objective laws) are not capable of adequately explaining the behaviour of economic actors and their consequences, and therefore cannot adequately perform forecast functions. The relation between the objective and the subjective as the main component of the method of the economic theory requires a new approach.

The distinctive characteristics of behavioural economic theory as a separate scientific direction are in the rejection of the "three whales" - the prerequisites of rationality, the pursuit of self-interest and balance. Behavioural economics is being shaped as a new direction, within which attention has been shifted from developing formal models of rational behaviour of an individual in various situations of choice to the process of their experimental and empirical testing, to determine the degree of consistency (divergence) of traditional economic theory and patterns derived from it the facts of economic activity. The behavioural approach, inherent in the activities of various subjects: from the individual and the company to the markets and regions, is systematically reproduced, complicated, and reveals the underlying motives of the agents who do not always follow the canons of the traditional economy.

The first ideas of behavioural economics are reflected in the works of famous economists: Adam Smith (1723-1790), one of the founders of economic theory as a science, Alfred Marshall (18421924) - one of the founders of the neoclassicism, John Keynes (1883-1946) - founder of macroeconomics as a separate science. In the works of these authors, the theory of a rational "economic man", whose purpose is to obtain benefits and income, was formed. The defining feature of the concept is rationalism and egoism; that is, the desire of the subject to maximise their benefit. The idea of "economic man" dominated economic theories for an extended period. J. Keynes first expressed the concept that irrational factors influence financial and economic processes.

However, more profound studies of irrational principles were possible only at an interdisciplinary level. Thus, Keynesian theory contributed to the formation of such models that suggested too unrealistically high cognitive capabilities of the individual. Subsequently, in the controversy of new classics with new Keynesians, the latter put forward provisions on price rigidity and nominal wages as opposed to their flexibility and the possibility of a quick automatic transition to a new equilibrium. Another idea - the complete rationality of individuals (and their expectations) - was not taken into account as an object of constructive criticism. The framework of this concept did not confuse the researchers as long as the researchers were economists.

Institutionalists Thorstein Veblen, John Commons, John Dewey believed that the rational approach is not the only thing that determines economic and financial behaviour, the essential elements in comparison with it are institutions, habits and customs. T. Veblen in his concept of conspicuous consumption explains the wasteful spending on goods or services with the primary goal to demonstrate consumer's wealth, and such 
behaviour serves as a means of achieving or supporting a certain social status. Veblen believed that individuals are constantly driven by competition, they are in a state of constant comparison their way of consuming with the other's way, determining through their consumption their position in society and the position of those around them. From the institutionalists' point of view, this behaviour is the primary determinant of consumer activity in households. Scientists have identified several effects associated with conspicuous consumption, in particular, the impact of Veblen: the increase in consumer demand because the product has a higher price that consists of two components. First, the real and prestigious prices; second, the effect of snob and effect of following the majority.

At the beginning of the 20th century, a separate branch of psychological knowledge appeared economic psychology. The development of the industrial branch of economic psychology is associated with the name of Hugo Münsterberg, and the marketing branch that received the initial development in Western psychology was laid by Gabriel Tarde. It covers the psychological problems of exchange, distribution and consumption. One of the most prominent representatives of the marketing branch of economic psychology was the American psychologist George Katona.

Behavioural game theory has made a significant contribution to the development of behavioural economics. Behavioural game theory is a direction of game theory that evaluates the behaviour of other people and suggests their further actions to make profitable decisions (Camerer, 2001).

This line of research focuses on three areas (ibid.):

Mathematic theories explaining the social interaction of people at the auction and the establishment of trust between them;

Limitations of strategic behaviour and cognitive ability to account for the steps of competitors;

Modification of strategies in the process of training people in practice.

The use of mathematical mechanics of game theory in the field of economics and finance in the second half of the last century proved to be extremely fruitful. To the greatest extent, this was manifested in those sections of the theory, the object of consideration of which is the strategic interaction of economic and financial agents among themselves in various conditions and the desire to solve the arisen conflict situation in the most optimal way.

Principles of game theory:

The principle of rationality;

Principle of general knowledge;

Principle of elimination of dominated strategies.

The game theory proves that if players do not change their strategy, sooner or later they will come to some equilibrium state in which the gain can no longer increase by continuing to follow the chosen line of conduct.

The game with the ultimatum (was invented in 1982). This simple game situation has attracted enormous attention of scientists precisely because the results of experimental research were significantly different from the predictions of the formal game theory, which implies that the individual follows only his interest.

The game has two players and $\$ 100$ bills for one dollar. The first participant comes to the second participant and offers absolutely any amount of these \$ 100 at their discretion (a participant can offer zero). The second player has a choice: agree to the division proposed by the first player; or refuse sharing and then no one gets anything, $\$ 100$ is taken away by the organisers of the game. Participants cannot enter into negotiations. As a rule, a rational player will settle for any amount that is more than zero - it is better to get at least one dollar instead of nothing. If he is offered a zero, he does not make a difference to agree or refuse, and he will still receive 0 , regardless of his decision. Based on this, the most logical decision of the first participant will be to offer the second one $\$ 1$ and take \$99 to himself. However, these arguments are considered from the point of view of rationality and the theory of the games. Moreover, in real life, emotions, justice and greed will also influence the decision-making process.

Zero or $1 \$$ are offered very rarely because it is necessary to ensure that the second player agrees to the division. Most often, the first players offer the second from 30 to 50 per cent of the total. If the proposed amount is less than 30 per cent, then people begin to refuse more often (Henrich et al., 2004). The lower the amount offered, the higher the probability of the second player refusing to share. Although, as we said above, it would be rational to agree to any amount. Some people think that the offer is too small an amount of offence and adhere to the principle "no one gets the money", 
thus punishing the first player for greed. Results are affected by age, culture, education, aggressiveness, lifestyle, etc. Factors such as communication and familiarity between players influence. The closer the connection, the closer the distribution of money will be to a fair 50/50 (Sanfey, 2003). The experiments conducted by Morewedge, Krishnamurti and Ariely (2014) showed impressive results - the participants in the experiment who are intoxicated are more likely to reject unfair proposals than sober ones. Studies conducted in India in 2011 showed that the greater the amount to be divided, the fewer people refuse to distribute (Andersen, Ertaç, Gneezy, Hoffman, \& List, 2011).

Nash equilibrium - such a situation in which none of the players can increase their winnings, unilaterally changing their decision. In other words, the Nash equilibrium is a position whereby the strategy of both players is the best response to the actions of their opponent. An example of the Nash equilibrium is the situation on the oligopoly market when firms have to make non-cooperative decisions. There are two oligopolistic firms in the industry - Firm A and Firm B. If both these firms could agree with each other and raise prices on their products, they would receive a high profit of $\$ 5$ million. However, these firms are primarily competitors, and each has prerequisites to break its contract by lowering the price and thereby capturing a part of the market and getting even more profit of $\$ 7$ million. Naturally, after such actions of an opponent, the profit of another company has decreased and will be, for example, $\$ 1$ million. But in a real situation, trying to reduce risks and get around an opponent, each company will select low prices and make a profit of $\$ 3$ million each, reaching Nash equilibrium (see Fig. 1):

Pareto efficiency or Pareto optimality. A situation in a cooperative game in which a group of players gets the maximum win (equally for all who have cooperated), but any player has the opportunity to make a move unilaterally, increasing his winnings by reducing the winnings of other players. Under this rule, the right to all changes that do not cause any additional harm is recognised. In economics, a situation where Pareto efficiency is achieved is a situation when all the benefits from the exchange of the parties have been exhausted (Barr, 1992).

John von Neumann and Oskar Morgenstern, the founders of game theory, believe that the behaviour of an individual consumer depends on the behav-

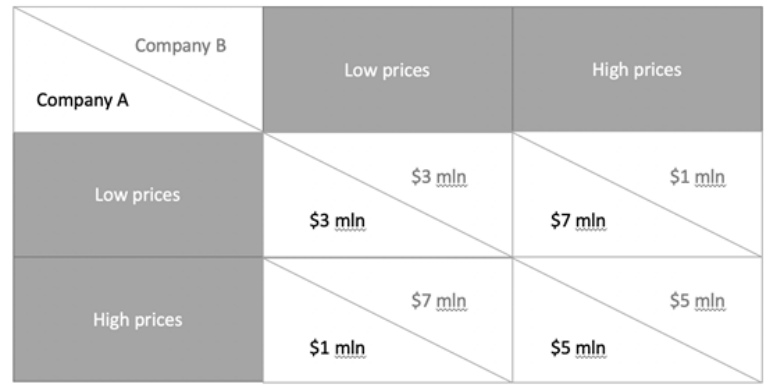

Fig. 1. Oligopoly pricing.

Source: The author.

iour of the other participants in the relationship. It follows that in the process of interaction between subjects about the consumption and distribution of disposable income, even stable belief systems can collapse, and then other people's behaviours are chosen. The results of research by economists gave an additional argument in favour of the fact that human nature is characterised not only by a desire for material interests but also by a desire for justice and cooperation with other people.

As an independent direction, behavioural economics in Western scientific literature appeared in the 1960-70s and actively developed by prominent psychological scientists Daniel Kahneman, Amos Tversky, Paul Slovic and economists George Akerlof, Robert James Shiller, Dan Ariely, Richard Thaler.

In the Russian economic studies, the first researches in the field of economic psychology belong to V. Sokolinsky, A. Kitov, S. Malakhov. A fundamental contribution to the theory of psychological economics was made by B. Raizberg, who identified three main areas of research: the psychology of monetary behaviour, the psychology of labour behaviour, and managerial psychology.

From the standpoint of behavioural economists, it is essential to explain the functioning of the economy and good governance, taking into account the psychological characteristics of human behaviour: changes in feelings, impressions and moods. The economic theory without taking into account subjective factors and the irrational beginning creates an erroneous understanding of economics and finance, which in practice can lead to negative results and loss.

\subsection{Theoretical aspects of the decision- making process under risk and uncertainty} In the standard model of the information economy, time and effort required to solve problems are treated as expenses. Behavioural research- 
ers have studied in more detail how decisions are made in situations of expanding the selection and complication of products. Some findings showed that consumers use relatively simple rules of heuristics; that is, they ignore some possible options due to a large amount of labour-intensive information. Economic and financial agents use heuristics to optimise the decision-making process in such situations, especially in conditions of time constraints, when decisions should be made quickly. In many cases, this is an effective way to achieve an optimal solution. However, these "rules" can also lead to incorrect results.

Economic agents often face solutions that involve some degree of uncertainty. An obvious example is buying insurance when consumers pay a fixed amount to limit costs in the event of an accident (for example, a car accident or severe health problems). There is also a significant degree of uncertainty about the future, when economic agents borrow, make savings and investment decisions. Traditional economic models suggest that consumers, faced with the problem of choice with an uncertain outcome, evaluate the possible results depending on the probability of their occurrence and make a choice with the highest expected benefit, that is, maximise the expected utility. At the same time, consumers evaluate risky decisions in an appropriate manner.

Deviations in the behaviour of economic agents explain the "Prospect theory" by Daniel Kahneman and Amos Tversky, associated with decision-making under risk. They called it a prospect theory because it highlights how people make decisions based on their prospects. The prospect theory reads as follows:

There is a value function of subjective value that reflects how people value different things for themselves.

There is a second component - the weighting function, which reflects the attitude of people to probability (Kahneman \& Tversky, 1979, p. 263).

This model is based on three cognitive principles of consumer choice:

The assessment of possible consequences is carried out in relation to the neutral point of reference, or level of adaptation.

The principle of desensitisation works in assessing the dynamics of wealth.

The principle of non-acceptance of losses. Consumers are ready to incur additional costs to avoid significant losses but are not ready to go to such expenses to achieve great success. Losses are experienced more than gain.

Based on experimental data, scientists derived a value function, which was determined in terms of deviations from the original value. The curve is convex upward for winnings and concaves downward for losses, which means risk aversion to winnings and riskiness to lose, and the value function has a steeper slope on losses than on winnings (see Fig. 2).

The asymmetry of the perception of winnings and losses is due to the fact that the human psyche perceives not so much the absolute value of its wealth, as its change, and the pleasure of winning is less than the disappointment of defeat. Costs always seem more significant than the equivalent income. Based on experimental research, the theory of perspective draws a paradoxical conclusion: people are more likely to take higher risks to avoid costs than to get an extra bonus with a lot of risk. For example, mass storage of money in the form of cash, despite recommendations for more rational use and support of the national economy, is explained by the natural feeling of "not taking costs", reinforced by negative experiences acquired during the times of hyperinflation, voucher privatisation and "financial pyramids".

A person tends to dwell on his initial choice (anchor effect), and then make decisions that are consistent with him. At the psychological level, such a mechanism serves as self-defence against the awareness of the fallacy of the decision made. In this case, the initial choice may be random, but the subsequent line of conduct will be quite natural.

An equally important effect - the effect of negative bait - is to introduce an additional choice opportunity only to capture the consumer's attention (see Fig. 3) in order to impose on it the most profitable purchase for the seller. In the first variant, the consumer selects according to the classical price-quality scheme, in the second, the consumer usually chooses case A from any options, since he compares his preferences to an anti-bait $(-A)$.

In other words, additional information may distract consumers from more important factors, and this can adversely affect consumer choice and make them make less profitable decisions.

Moreover, such phenomena as optimism, overconfidence, availability heuristics, hindsight bias errors, turn out to be not just typical but also mass phenomena both in economic practice and in everyday life. 


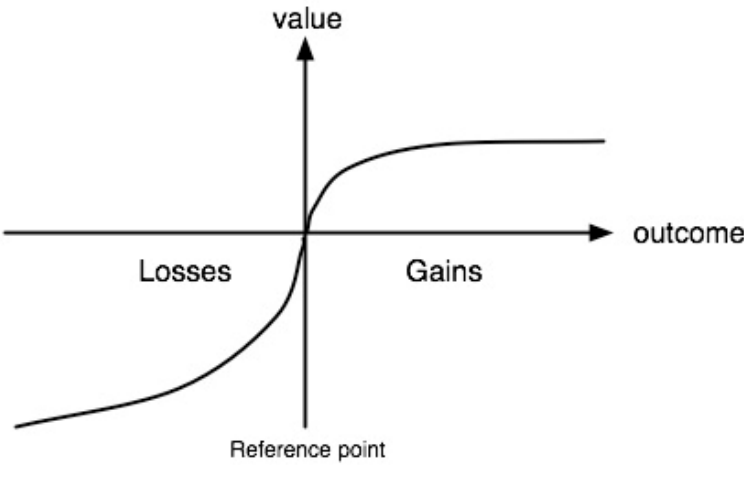

Fig. 2. The utility function in behavioural economics.

Source: Tversky \& Kahneman, 1992, p. 313.

An interesting point in the selection process is the relative probability. Depending on the context, the circles in the centre seem to be different, although, in reality, they are absolutely identical (see Fig. 4). Behavioural researchers emphasise that this is how consumers make choices. The effect of relativity is closely related to the demonstrative effect of consumption, consumers often imitate neighbours, friends, TV stars.

The widespread use of credit cards reveals the irrationality of human behaviour. Consumers make a choice every day from several alternatives, and everyone, in principle, is able to assess the possible consequences of decisions made. People face constant trade-offs between current consumption and future consumption; Besides, the situation in which they are today depends mainly on the choices made in the past. Standard economic models of intertemporal decision-making assume that consumers choose the value of current and future consumption by discounting, which is consistent between two periods, regardless of when the consumer makes estimates. Behavioural economics argues that consumers value the present more highly than other periods. From here, they make shortsighted decisions regarding savings and loans. These consumers may, for example, take a small loan today at a higher interest rate instead of a larger loan in a year at a lower discount rate.

In a general sense, the risk is an economic category expressing relationships about achieving a certain degree of success (failure) in the implementation of its goals by a business entity, taking into an account controlled and uncontrolled factors of activity. Often the risk is understood as the probability of the occurrence of any event. If
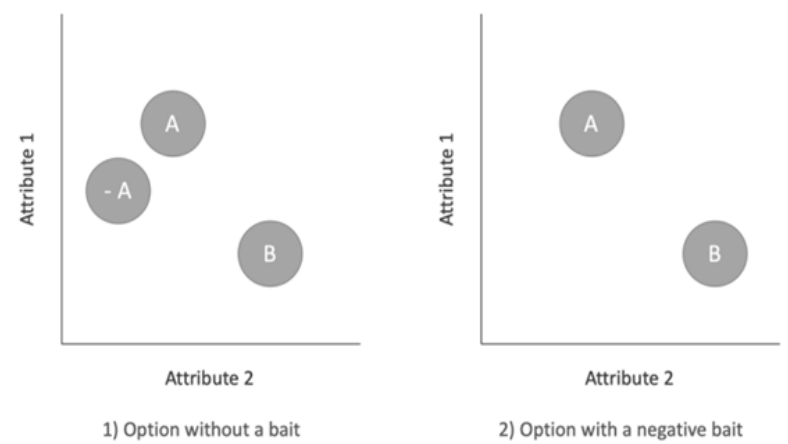

Fig. 3. The anti-bait effect when selecting from several alternatives.

Source: The author.

such an event occurs, three economic outcomes are possible: negative (loss, damage, loss), zero, positive (win, chance, profit). One can take this probability into account by streamlining the expected impacts according to the likelihood of their occurrence.

The risk we characterise as the unity of objective and subjective beginnings. On the one hand, it is generated by objective factors and exists independently of the will and consciousness of people. On the other hand, the risk is associated with the choice of certain alternatives by a specific person, which bears in itself the stamp of individuality, psychological make-up, personal motives. The occurrence of risk is determined by the probabilistic nature of many processes, unforeseen, accidental circumstances, the multivariance of economic relations into that business entities enter. People usually make decisions in the absence of complete information and certainty. In such a situation, there is a risk that the desired result will not be achieved. With uncertainty, the probability distribution of certain events is unknown. In this case, the estimated net benefit is calculated based on pessimistic, optimistic and intermediate estimates (George et al., 2017). Depending on the individual risk attitude, people make decisions that they consider to be correct.

Depending on the different attitude of consumers to risk, there are several types:

Risk-takers - risk-averse, easy-to-take (assuming that the gain may be less than the initial payment);

Risk-neutrals - individuals that are neutral to risk (relying on expected gains);

Riskophobes - risk opponents (investing an amount strictly less than the expected income). 
In many cases, the risk is taken when external circumstances require it. However, most agents do not expect to get a big win and only seek to avoid losses. Often this leads to the choice of a slower, but more reliable course of action.

The empirical study of strategies for repayment of multiple debts described in Psychological Factors of Multiple Debt Repayment Strategies (Gagarina \& Goroshnikova, 2018) with 350 respondents reflect six different decision-making groups depending on psychological traits and attitudes to risk (see Fig. 5):

Rational strategy is repayment of the debt, taking into account rational factors and only in that case a game is completed with a positive outcome.

Semi-rational respondents try to reduce the total amount of debt, their actions are analytical but still not totally rational, and they are more risk-taking higher curiosity and flexibility.

In terms of chaotic strategy, respondents have multiple errors in fulfilment of the task of paying off multiple debts; they are less open to new experience, not curious and flexible.

Aversive strategy respondents reduce the total number of arrears more typical for women than for men. Respondents make some mistakes.

Distributive respondents pay off all or some debts not wholly closing them.

Ignorance of small numbers. Respondents with a strategy for paying off debts ignoring small amounts turned out to be more benevolent.

Behavioural economics explains any economic phenomena on any scale through the lens of psychology, rationality/irrationality and behavioural mechanisms.

Irrational beginning - the management of non-economic motives, irrational behaviour, persistence in delusions, spontaneous determination to act, disorder, illogic. Irrationality, as an integral feature of economic behaviour, must be taken into account when modelling. Hence, the causes of the crisis: well-established ideas, changes in attitudes, approaches to business, loss of trust, a sense of justice, ignoring the role of abuse and the sale of low-quality products - do not attach importance to stories interpreting economic mechanisms.

The behaviour of agents on the market is determined by the irrational beginnings of a person, creating waves of optimism and pessimism. Behavioural economics is based on the axioms of a partial, but significant lack of understanding
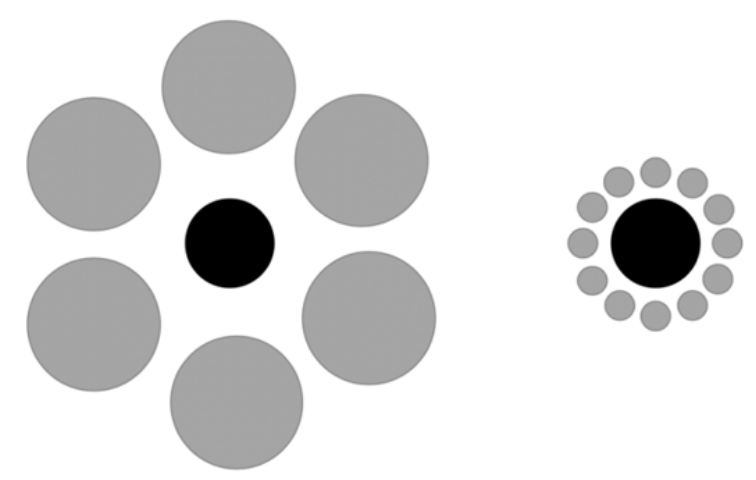

Fig. 4. Illustration of the principle of relativity in the selection process.

Source: https://epee.hse.ru. Accessed 03 April 2019.

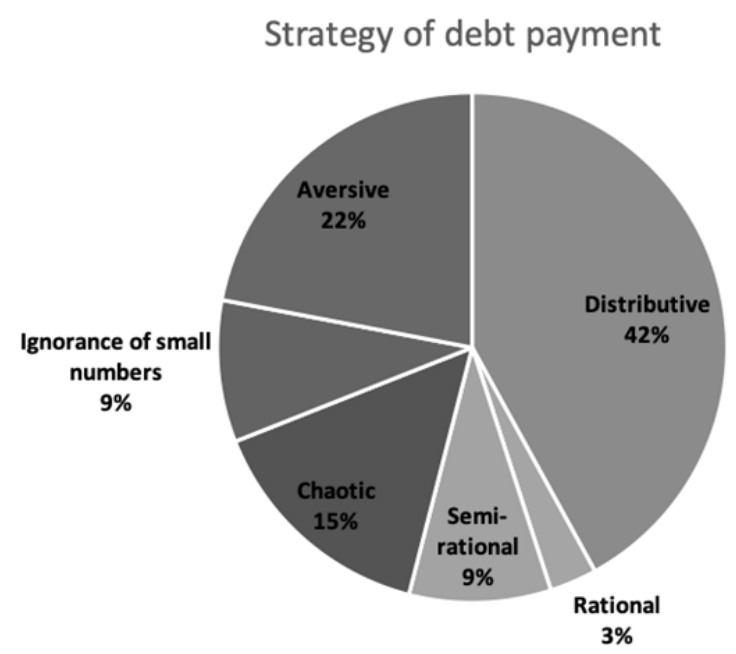

Fig. 5. Representativeness of strategies.

Source: Gagarina \& Goroshnikova, 2018, p. 60.

by individuals of the laws of market functioning, which is especially evident during periods of crisis. Individuals perceive only a small part of the total amount of information due to the complexity of the economic world. Therefore, despite the desire, they cannot make the optimal choice prescribed by theory.

Testing, interpretation of economic mechanisms for any economic cycle, the ubiquity of application for different countries add a new dimension to existing models that are not able to explain the euphoria, which is replaced by pessimism. Economic reality includes many psychological variables that cannot be reflected using traditional models. Trust, honesty, optimism, irrationality, motives of behaviour, opportunism, risk, viruses, etc., are the subject of behavioural economics, which ensures the effective management of economic systems. 


\section{Irrationality in the Process of Making Financial Decisions}

\subsection{The main problems of decision} making associated with the assumption of "rationality"

The traditional approach to understanding individual decision-making is based upon classical decision theory and the rational economic model. These were initially developed in economics, and they make certain assumptions about people and how they make decisions. The rational economic model of decision-making (see Fig. 6) is still popular among economics scholars in suggesting how decisions should be made. However, to understand its weakness it is necessary to list its assumptions and demonstrate how they fail to match up to reality (see Table 1).

The classical view of decision-making employs the concepts of rationality and rational decisions, in its discussions and prescriptions. Rationality is equated with scientific reasoning, empiricism and positivism; and with the use of decision criteria of evidence, logical argument and reasoning. Rational decisions are decisions which are based on rationality, that is, on a rational mode of thinking.

The classical view has now been accepted as not providing an accurate account of how people typically make decisions. Moreover, its prescriptions for making better decisions have often been incorrect. Instead, contemporary cognitive research by psychologist has revealed how decisions are made based on heuristic models, judgements and tacit knowledge.

Descriptive models of decision-making focus on how individuals actually make decisions. Each decision made by an individual or group is affected by several factors. Some of these include:

Individual personality;

Group relationships;

Organisational power relationships and political behaviour;

External environmental pressures;

Organisation strategic considerations;

Information availability (or lack of).

The aim of these models is to examine which of these factors are the most important, and how they interrelate before a decision being made. One of the earliest, and still among the most influential descriptive models, is the behavioural theory of decision-making. It was developed by Richard Cyert, James March and Herbert Simon. It is called

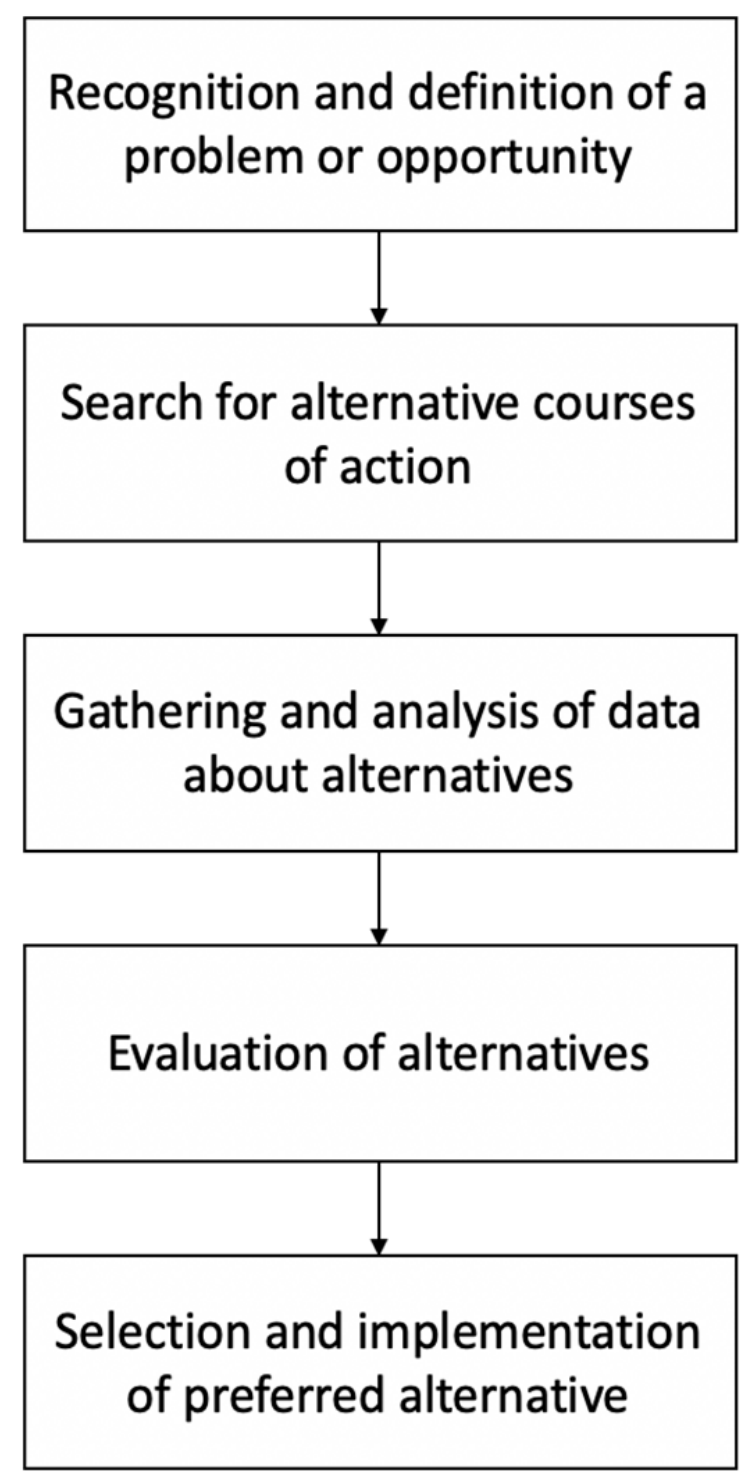

Fig. 6. Rational economic model of decision-making. Source: Buchanan \& Huczynski, 2017, p. 312.

"behavioural" because it treats decision-making as another aspect of individual behaviour. For example, if a research study interviewed brokers who bought and sold shares in the stock market to determine what factors influenced their decisions, it would be an example of a descriptive approach to decisionmaking. It is also sometimes referred to as "administrative model", and it acknowledges that, in the real world, those who make decisions are restricted in their decision processes, and therefore have to settle for a less than an ideal solution. The behavioural theory holds that individuals make decisions while they are operating within the limits of bounded rationality. Bounded rationality recognises that:

The definition of a situation is likely to be incomplete

It is impossible to generate all alternatives 
Table 1

Rational economic model assumptions and reality

\begin{tabular}{ll}
\hline \multicolumn{1}{c}{ Assumption } & \multicolumn{1}{c}{ Reality } \\
\hline All alternatives will be considered & $\begin{array}{l}\text { Rarely possible to consider all alternatives since } \\
\text { there are too many } \\
\text { Some alternatives will not have occurred to the } \\
\text { decision-maker }\end{array}$ \\
$\begin{array}{ll}\text { Impractical to consider all consequences } \\
\text { The consequences of each alternative will be }\end{array}$ & $\begin{array}{l}\text { Impractical to estimate many of the consequences } \\
\text { considered }\end{array}$ \\
& $\begin{array}{l}\text { Estimation process involves time and effort } \\
\text { Accurate information about alternatives is available }\end{array}$ \\
The information available is rarely accurate, often \\
dated, and usually only partially relevant to the \\
problem \\
It costs money to be generated or purchased \\
Decisions have to be made on incomplete, insufficient \\
and only partly accurate information \\
Individuals lack the mental capacity to store and \\
process all the information relevant to a decision \\
Frequently they lack the mental ability to perform the \\
mental calculations required
\end{tabular}

Source: Buchanan \& Huczynski, 2017, p. 314.

Impossible to predict all the consequences of each option

Final decisions are often influenced by personal and political factors.

The effect of personal and situational limitations is that individuals make decisions that are "good enough" rather than "ideal". That is, they "satisfice”, rather than "maximise”. When maximising, decision-makers review the range of alternatives available, all the same time, and attempt to select the very best one. However, when satisficing, they evaluate one option at a time in sequence, until they alight on the first one that is acceptable. That chosen option will meet all the minimum requirements for the solution but may not be the very best (optional) choice in the situation. Once an option is found, decision-makers will look no further. The contrast between the rational decision-making described previously, and the bounded rationality discussed here is shown in Table 2.

Prescriptive models of decision-making recommend how individuals should behave to achieve the desired outcome. It makes the classical model described earlier, also a prescriptive one. Such models often also contain specific techniques, procedures and processes which their supporters claim will lead to more accurate and efficient decision-making. They are often based on obser- vations of poor decision-making processes, where key steps might have been omitted or inadequately considered. They are developed and marketed by management consultants as a way of improving organisational performance through improved decision-making.

Victor Vroom and Philip Yetton developed one of the best known prescriptive models of decisionmaking, later expanded by Vroom and Arthur Jago. The focus is on decision-making situations, and on seven factors to identify the decision-making style that is likely to be most effective in any given case. It focuses on decision style, concerning how a leader decides in a given decision situation, rather than what a leader chooses to. It also concentrates on subordinate participation - the appropriate amount of involvement of the leader's subordinates in making decisions. The model consists of three main elements:

Decision participation styles.

Diagnostic questions with which to analyse decision situations.

Decision rules to determine the appropriate decision participation style.

Two key concepts underpinned the model quality and acceptability. The quality of the decision relates to it achieving the aim; the cost of its implementation; and the time taken to implement 
Table 2

Rational decision-making and bounded rationality contrasted

\begin{tabular}{|c|c|}
\hline Rational decision-makers... & Bounded rationality decision-makers... \\
\hline $\begin{array}{l}\text { Recognise and define a problem or opportunity } \\
\text { thoroughly }\end{array}$ & $\begin{array}{l}\text { Reduce the problem to something that is easily } \\
\text { understood }\end{array}$ \\
\hline $\begin{array}{l}\text { Search for an extensive set of alternative courses of } \\
\text { action, gathering data on each }\end{array}$ & $\begin{array}{l}\text { Develop a few, uncomplicated and recognisable } \\
\text { solutions, comparable to those currently being used }\end{array}$ \\
\hline Evaluate all the alternatives at the same time & Evaluate each alternative as it is thought of \\
\hline $\begin{array}{l}\text { Select and implement the alternative with the most } \\
\text { value (maximise) }\end{array}$ & Choose the first, acceptable alternative (satisfice) \\
\hline
\end{tabular}

Source: The author, based on Kahneman, Diener, \& Schwarz, 2003.

it. The acceptability of the decision refers to subordinates and anyone else either affected by the decision or who has to implement it. Leaders and managers generally select the highest quality decision that is acceptable.

An explanatory model of decision-making looks at what decisions were made and aims to explain how they occurred. For example, there are studies of military fiascos which examine why generals took or failed to take, certain actions. Often these made by teams have also been studied using concepts from the group level of analysis such as groupthink and group polarisation. Decisions such as whether to acquire or merge with another company have drawn upon the theories of conflict, power and politics, and have been explained at the organisational level.

The judgement heuristic and biases model represents the current thinking in decision-making. The studies have highlighted the limits to rationality and introduced the concept of bounded rationality. What else might affect the individual who makes decisions? Decision-making involves choice, and choice requires both careful thought and much information. Excessive information can both overload and delay. Many managers believe that making the right decision late is the same as making the wrong decision. Hence the process is speeded up by relying on judgement shortcuts called heuristic.

Decision-making using heuristics can be considered as a separate model and one that represents a further step away from the classical model. Robert Cialdini identified the decision-making biases and heuristics that could be used by individuals to influence the decisions made by others. He called them "weapons of influence":

Contrast. This bias of human perception affects the way that we see the difference between things that are presented one after another. If the second item is somewhat different than it actually is. If you lift a light object first, and then a heavy object, the latter will appear than it actually is.

Reciprocation. A basic norm in society is reciprocation, that is, one person must try to repay in kind in the future, what another has provided them with in the past. We are socialised from childhood to abide by the reciprocation rule or suffer social disapproval and a feeling of personal guilt. Such reciprocation leads to concession-making and allows different individuals' initial, incompatible demands to become compromised so that they finally work together towards common goals.

Commitment and consistency. Commitment is a state of being in which individuals become bound to their actions, and through these, to their beliefs. Commitment sustains action in the face of difficulties. In these circumstances, it is behaviour which is being committed. It represents a visible indicator of what people are and what people intend doing. After taking an initial decision, people will adjust their attitude to make it consistent with their action, and become committed to it.

Social proof. People decide what to believe or how to act in a situation by looking at what others believe and do. In case of uncertainty and ambiguity, they observe and follow others, especially those they perceive to be similar to themselves. Such similarity is defined in terms of status, social background, dress, manner or language. Market research suggests that 95 per cent of people are imitators, and only 5 per cent of people are initiators.

Liking. We enjoy doing things for people we like. That liking encourages us to comply with their requests. The liking bias is so powerful that the person concerned does not even have to be present for it to 
be activated. Often, just the mention of a friend's or mutual acquaintance's name will be sufficient.

Authority. Each of us has a deep-seated duty to authority and will tend to comply when requested by an authority figure. Since the opposite is anarchy, we are all trained from birth to believe that obedience to authority is right. The strength of this bias to obey legitimate authority figures comes from systematic socialisation practices designed to form in people the perception that such obedience constitutes correct conduct. Different societies vary its terms of this dimension.

Scarcity. Things and opportunities that are difficult to obtain are more valued. We use information about an item's availability as a shortcut to decide quickly on its quality. As things become less available, we lose freedoms, and since we hate this, we react against it and want these things more than dimension.

As individual decision-makers, we all use judgement heuristics to reduce the information demands placed upon us. Considerable mental activity is saved by summarising past experiences into the form of heuristic and using them to evaluate the present problems. Similarly, managers in organisations substitute such simplifying strategies to save having to collect complex information and analyse it. While helpful in many situations, heuristics can lead to errors and systematically biased judgements. Although the three main biases have been discussed, many other errors, fallacies and biases exist. People have ideas about the order, randomness, chance and so on. Studies have shown how peoples' judgements become biased and hence, less rational.

\subsection{The main mistakes made on the stock market}

Adherents of the classical theories of financial markets against the researchers of irrationality in financial markets have always heard many accusations. Most of them consisted in the fact that the facts of the irrational, ineffective behaviour of operators in the market are unsystematic in nature and, ultimately, are regulated and levelled by the rest of the market. Is it really so? Does the market really have the ability to swallow a nonstandard investment activity? Or does it function with systematic errors that investors are not aware of, who are influenced by the same deviations? To understand this crucial issue, scientists in the field of behavioural finance conducted a considerable amount of research. Empirically, it was proved that when they find themselves in situations where they need to make an investment decision or to make a prediction, operators in the market tend to make the same mistakes repeated from one time to another.

As such, the effects, which will be discussed below, do not have any market pegs. They take place in any stock market, be it the USA, Russia, or the other side. They are determined by the stereotypes of financial thinking, the lack of necessary diversification of financial knowledge, in some cases, the routine of the work performed, and, consequently, the narrowing of the skills used and the required amount of knowledge. All this leads to the fact that most of the operators, regardless of a national peg, get into a situation when the methodology they use is not applicable for making a successful investment decision.

Many investors do not anticipate what impact they may have on the results of their investment activities. As a source of collecting, analysing and processing large amounts of information a person without loss of quality, a person does not fit very well. This position of many scientists is reflected in practice when time after time, a person shows his inability to process numerical arrays and make the right investment decisions.

Some behaviourists believe that this phenomenon is caused by the fact that in the modern digital, information space, a person lives by entirely different laws than his ancestors, who lived thousands of years ago and the main choice for them lay in the area of their natural, biological needs and needs. This position may seem absurd, but it undoubtedly has the right to life, because, as practice shows, the individual is still inclined to use the mechanisms of dismemberment and simplification of information used by our ancestors. The concrete way in which these mechanisms of a person's adaptation to the problem before him are expressed and what results their use leads to will be discussed later.

When carrying out financial activities, there is always uncertainty on a scale. It is almost impossible to take into account the totality of factors that determine the functioning of a process, whether it is pricing or risk identification. To be able to apply any measures to minimise the effect of uncertainty on the processes, one should calculate the probability of occurrence of a particular event.

However, financial market participants use vast flows of information in their work and make their 
decisions according to them, and the calculation of the exact probability becomes a very laborious process. Again, if this process is accelerated by reducing the number of factors taken into account, then the final value of the probability of an event occurring will only be approximate and not capable of reflecting the real chance of a particular event occurring.

In such cases, many operators take a different route to avoid substantial labour costs. Moreover, the determination of the probability for operators becomes dull, and it becomes possible to apply this method to future similar situations. The ease of application of the heuristic approach and application determines the breadth of its distribution in the financial and domestic environment.

The heuristic approach is to apply any operator skills, be it his previous experience, sensations or expectations to solve problems, usually requiring the use of more complex mechanisms for its solution.

The efficiency of heuristics directly depends on the situation in which it is applied. Some are quite effective; others are the opposite. Concerning financial markets, it can be assumed that heuristics are not a rational solution. There are three types of heuristics most commonly used:

1) Access heuristics

2) Representative heuristics

3) Heuristics of fastening and adaptations.

Considering the heuristics of representativeness, one must, first of all, determine the essence of this concept. This heuristic is a judgment about a process or person based on stereotypes. The danger of frequent use of this heuristic is that representativeness initially ignores some factors that most often are decisive in making the right decision or judgment.

These factors include:

A) Misconception about the chance

B) Insensitivity to basic probabilities

C) Insensitivity to predictability

D) Insensitivity to sample size

E) The illusion of significance.

Let us briefly consider these factors in turn. The misconception of a chance is because many operators believe that if there is any random process, then the generation of events by them in a long and short period will be identical. It is wrong. An example is a coin flip, an example of a classic and vividly demonstrating an incorrect interpretation of a chance. At the subconscious level, many believe that a sequence of eagle-tail-eagle-tail-tail is more likely than a tail-tail-tail-eagle-tail.

Mathematically, this statement has no basis, since the subsets of a process do not always bear the characteristics of a common set. They can cause serious deviations, which are only aggravated by the small sample size.

Because of this phenomenon in the financial markets, there are two effects, the effect of the "hot hand" and the "player's delusion". The first is to re-evaluate one's capabilities because of the consistent onset of operator-friendly events that were generated by a random process. As a result, this leads to de-mathematisation when making important investment decisions and losses.

The second, "the player's delusion" is the opinion formed by the operator that the chance is a self-regulated value, and at certain predetermined intervals, each deviation in one direction will be levelled by movement in another.

These effects are the result of not understanding the law of large numbers. Kahneman and Tversky gave this phenomenon the name of the "law of small numbers", which says that people will consider even small samples to be representative of those from which they are derived.

Insensitivity to basic probabilities. The next factor that is not taken into account when using representativeness heuristics is the size of the initial probability of an event. It would seem, how can a person, evaluating various scenarios, not take into account the most fundamental information. It is empirically proven to be possible. To do this, let's consider one study (Kahneman, Slovic, \& Tversky, 1999) conducted by scientists to confirm the existence of this systematic error.

Were randomly recruited respondents who were asked to determine the profession of a person by his characteristics. One respondent was told that in a sample of 100 people, 70 were lawyers, 30 were engineers, and other respondents, on the contrary. For example, the following characteristic was proposed: "John is 29 years old. He is married and has no children yet. Active and purposeful, he is satisfied only with success, and constant movement forward. He is highly respected by his colleagues."

As can be seen, no specific information indicating John's occupation was provided, therefore, the likelihood that he is a lawyer or engineer should 
remain unchanged within the previously specified ratio. As a result of the study, it turned out that both groups of respondents indicated approximately the same probability that this person is a lawyer -0.5 . Initial probabilities were ignored. But it should be noted that such results were achieved only in cases when the respondent was provided with additional information that did not carry any useful information. If there was none, the respondents were close to real probabilities by their estimates. This phenomenon has been confirmed several times, both through research among ordinary respondents and among professional market participants. As a conclusion, one can say that a person objectively assesses probabilities only when he has only the basic necessary information. In a situation where the operator has any additional pseudo-information, his ability to correctly assess the possibilities of developing a certain process is reduced to a minimum.

Insensitivity to predictability. Quite often, operators in financial markets are faced with the task of predicting the size of any quantities, whether it is the price of a stock, the size of profits in the future, the demand for any services. In this case, without having the ability to quickly and mathematically calculate these values, the operator gives his picture of the development of events, using the moment information about the object of forecasting.

It is possible to take as an example the situation when a person has a description as issuer, without specifying specific indicators of its activity. Of course, if the description of this company is positive, any person will consider the future high profits of this company more representative than the losses. And, accordingly, vice versa.

Here lies the analyst error. Based on what it is possible to give a high assessment of the future results of the enterprise, without having mathematical tools and current performance indicators?

Insensitivity to sample size. One of the most common mistakes, partly described earlier, is the substitution of the law of large and small numbers in the mind of an individual. Because of this, there are often cases when errors occur in the prediction of all sorts of phenomena. Insensitivity to sample size is one of the factors that characterise the heuristic of representativeness. Take an example. If the task is to determine the likelihood that the average height of randomly selected ten men will be 180 centimetres, it is quite natural to apply in this case information about the average of these indicators among all men in general. It turns out that, statistically, the respondent denies the possible deviation of this sample, about which he has no information, and uses his empirical data to determine the probability in a situation where he is not able to reliably determine the probability. Thus, as a result of the experiment, the probability data obtained from respondents were approximately equal for samples of 10,100 , and 1000 people.

In addition to this common aspect of forecasting, there is also a phenomenon called the "conservatism effect". We give an example clarifying its action.

In 1968, this effect was studied by the American scientist Ward Edwards in his paper (Edwards, 1968). And there he gave the results of the next experiment. Suppose we have two bags, in each of which there are 1000 chips, in one of them there are 700 red and 300 blue, in the other -700 blue and 300 red. If we take a coin and throw it to determine the bag that we take for the experiment, then the probability that we take the bag with the prevailing blue chips is 0.5 . Then, the respondent needs to determine the probability that this bag is really with 700 blue chips, provided that of the 12 elongated chips, 8 were blue, and 4 red. Naturally, the probability that this "blue" bag is now higher than 0.5 . If you give a probability of this equal to 0.7 or 0.8 , then you fall into the group of the majority of respondents, and the majority is wrong in your assessment. The exact probability is 0.97 .

The illusion of significance. In light of the above, it is already clear that people often abuse the reduction of the outcome of the forecast to the description of the process. And the operator's confidence is the higher, the higher their similarity. Therefore, if there is an opportunity to identify the process and its result, then the operator will always do it, regardless of the quality, completeness and statute of limitations of the description of this process.

The last moment is especially remarkable. Even if the operator is aware that the description of the process by which he needs to make a prediction, is lagging behind reality or contains any distortions, to save time, which he, he believes, can spend on other matters, he will often ignore this moment will give a prediction as if this information did not exist. It is this moment when the investor is so confident that he evaluates the uncertain process according to his description despite the scarcity of information on it and is called the "illusion of significance". 
Based on the preceding, we can conclude that it is rare when an investment decision is truly justified. Most often, the aforementioned heuristics are used for this. However, there is an effect of even deeper primitivistic of the investment choice. This effect is called the home bias.

It is quite natural that in everyday life, people rely on verified information, use things they are used to. If the individual is given a choice between using two things-substitutes, one of which is well known to him, then most often the choice will be made towards the latter.

This behaviour is also present in financial markets. According to statistics, market participants in different countries invest their money in the assets of the state of which they are citizens. Forming his portfolio from any national instruments, the investor naively believes that he is well-diversified, which is wrong. It would be reasonable to say that it is necessary to diversify a portfolio based on considerations of the share of different countries in the global financial market.

Let us take the example of a domestic investor. According to the above principle, at first glance, it appears that it is better not to invest money in the Russian stock market. Of course, this is not the case, especially in the case of limited investment funds. However, according to the theory of portfolio investment, a set of assets from one investor cannot be called fully diversified. After all, all the papers of one national market are equally affected by country risk, which was especially clearly demonstrated by the crisis in the United States. Let this example be in some way unique, because the collapse in the United States has pulled other markets along with itself, but it is vividly demonstrating the essence of national diversification. Financial crises in different countries are not always related in time, and when constructing a portfolio of securities of the leading stock markets of the world, this will allow insuring against the loss-making of the entire portfolio.

Many operators in various segments of the financial market in one way or another overestimate their ability to predict a particular event. Faced in practice with the phenomenon for which they observed and about the features of the development of which they had some idea, investors often use the ultimate significance of this process to work out a hypothesis. That is, they build their model for the development of this process, which is not always true.
The investor, having obtained the result, is trying to integrate this value into the existing information system. Having laid out the processes that affected the outcome, the investor understands the weight of each of the factors in the final result. He becomes all clear, especially if he knows the methodology. The thought arises that, as it should be thought, the investor could predict the same outcome until the moment when its value would be known.

This deviation is dangerous because, as a rule, such situations are used by the investor to make a "routine" out of it, that is, to use the experience gained to apply to future situations.

It begins to bring negative consequences as soon as the evaluation methodology starts to lose sight of any factors affecting the outcome. This deviation at the micro-level of the investor takes place at the beginning of his activity, then it decreases to the extent of his influence on the activity, and after a more or less long period, he begins to influence his work as he gains experience in a certain area and, therefore, the investor's excessive confidence in his ability to predict the outcome of a process.

To materialise the concept of "excessive self-confidence" and give it a financial justification, consider some statistical data on the US stock market and try to identify the relationship of its revaluation and financial results from this effect.

In 2001, scientists Brad M. Barber and Terrance Odean (2000) conducted a statistical study of the financial activities of 38,000 households operating in the securities market to buy and sell these securities through broker companies. The sampling period was six years and was carried out from 1991 to 1997.

In the standard practice for the analysis of trading activity is used an indicator called the "annual turnover of the portfolio". It is measured as a percentage and shows what proportion of the securities portfolio was sold and replaced with other securities. For example, an indicator of 50 per cent indicates that exactly half of the stock portfolio has been sold. If the figure is 250 per cent, then this means a double updating of the portfolio and the subsequent replacement of another half of the portfolio assets replaced.

For a deeper structure of the study, they introduced gender and family divisions; as a result, there were four groups: single men and women, married men and women.

For single men, the annual portfolio turnover is 85 per cent, for married men, 73 per cent, for mar- 
ried women, 53 per cent, for single women, 51 per cent. One can see how much lonely men develop a trading activity. Only 15 per cent of their securities in the portfolio per year were found by men from this group to be suitable for themselves and their investment strategy. However, one should note that since the rates are annual, it is quite possible that for the next year, those papers were replaced in the investment portfolio by others.

For the interrelation of gender, self-confidence and financial performance indicators, it is necessary to consider the study of Odean and Barber (2000) concerning the connection of trading activity with the financial result. For this purpose, 78,000 households that used brokerage services were included in the sample.

First of all, the meaning of trading in the stock market for a single investor is the extraction of income. At the same time, since the investor uses the paid services of a broker, then he faces the need to cover and commission. The size of the commission, of course, varies depending on the number of transactions initiated by the client. So, more deals - more commission. And the profit from resale should also significantly exceed the size of the broker's commission. And, accordingly, it is logical to assume that the yield from active trading should exceed the yield from passive portfolio management, that is, buy and hold strategies.

Investors from the sample were ranked by the rate of updating the securities portfolio into five groups, 20 per cent of investors in each. The first group, with the least high rate of renewal, is about 2.4 per cent per year. The last, for the most active group, an indicator of annual portfolio renewal held at the level of 250 per cent. For these groups, the average yearly rate of return was calculated. For all five groups, the yield was close to or equal to 18.7 per cent.

It turns out that all efforts to select paper, buy, and sell securities are in vain, without bringing additional returns that justify the high costs of active portfolio management. Moreover, this is a return that does not include transaction costs, taxes and other costs. After deducting payments due in all groups, it was found that the net yield for the group with the lowest renewal rate is 18.5 per cent, and for the most active, 11.4 per cent. The difference of 7.1 per cent per annum is a considerable amount, especially if you make a differentiation by the number of sums used for investment. The difference of 7 per cent per annum from $\$ 10,000$ and $\$ 500,000$ is incommensurable.

In addition to the purely quantitative problems considered, excessive trading activity leads to difficulties of a qualitative nature. Another mini-study was conducted on the most active trading group. The average yield of the paper sold and purchased for this group was determined for four months and one year. It turned out that the paper sold would have yielded a yield of 2.6 per cent for investors from this group for four months, while the purchased one would be 0.11 . In one year, the loss of profitability from such an operation is 5.8 per cent.

This phenomenon suggests that the most active investors tend to sell even the most profitable of their assets in favour of low-quality securities. We would repeat that this study did not take into account the lots of purchases and sales of securities, but only the focus of the transaction and the characteristics of the papers participating in it. Potentially profitable securities in practice turned out to be assets of worse quality than those that were sold earlier.

Accordingly, very often increased investment activity affects the highest-quality securities for portfolio renewal, which most negatively affects the financial result. Excessive self-confidence in the financial market is manifested in the form of a biased assessment of the risk associated with the activities of the investment operator. As a rule, there is an overestimation of the favourable outcome for an operator of an event, and an underestimation of a negative one.

That is, recalling that the group of single men correlates with the rate of portfolio renewal at 85 per cent with the group of households whose returns are at the level of 11 per cent per annum, it is logical to assume that the lower returns for them turn into less risk. It is a consequence of Markowitz's theory, the classical rule of any market, higher profitability should be sought in riskier assets, and vice versa. However, is this true in this particular case? The use of the coefficient of beta, as the indicator characterising the risk of a portfolio, turns out that single men have the highest beta coefficient and single women the lowest, that is, the papers are weakly correlated with the market movement.

It turns out that by buying papers with a higher risk, investors acquired low returns. It is since operators from this group had a high share in their portfolios of recently emerged companies, so-called 
small stocks, which, due to the characteristics of the organisation of their issuer, have a risk higher than the market average. Shares of such companies are acquired in anticipation of their rapid growth, which is not guaranteed by anyone. A rational investor seeks to limit the share of such securities in his portfolio, at least until he is convinced that a particular security paper is reliable in terms of risk and attractive in terms of its profitability.

It is where the relationship between gender, risk acceptance, over trading and financial results are revealed. Apart from the need to sufficiently diversify the portfolio, single men, who share the greatest trading activity, tend to sell their most liquid and high-quality securities in favour of small company stocks, hoping for a big gain, but in fact receive higher risk for low returns, which is even lower than the strategy of passive paper holding. In itself, the knowledge that overtrading leads to a final financial result that is less than the result of passive portfolio management of many scientists plunged into shock, but in addition to this, the relationship between overtrading and gender factor further enhances the impression of the results of empirical research by scientists.

\subsection{The main problems of management performance}

If an investor understands that his knowledge of the stock market and micro control is not enough to effectively invest in securities, more often, he transfers his money to the funds in trust management. At the same time, as a rule, they choose a fund that meets its investment preferences, the concepts of the risk/return ratio. After that, one could say that in the future, the funds will generate flows with precisely those characteristics that the founder of trust management expects.

However, it is not so. Unfortunately, the work of management companies is also extremely susceptible to individual behavioural deviations, which will be proved further by the example of a similar situation in the US market. The fact is that it is in trust management that the ineffectiveness of another concept of efficient markets about investor rationality is most clearly manifested. A rational investor equally avoids risk in loss situations and profit situations. In practice, the acceptance of risk in these situations is asymmetric.

For the representativeness of the experiment, Kathryn Sullivan (1997) invited to participate in an experiment to identify the characteristics of making financial decisions to 119 managers, each of whom had 20 years of experience in the financial sector and for at least six years occupied his current place. As a result, 96 financial managers took part in the experiment. Each of them had a task to choose two alternatives in five different situations, and the managers were warned that there was no right option; therefore, they ensured the originality of their investment decision during the polarisation of the experiment to the real market situation.

1) In the first experiment, the respondents were tasked to decide the condition of a probable loss of 600 thousand dollars. Managers in the condition of realisation of profits had the choice to save $\$ 200$ in the first case or with a probability of $1 / 3$ to save all 600 thousand, and with a probability of $2 / 3$ to lose them.

Managers in the condition of realisation of losses were asked to choose

A) Lose 400 thousand dollars

B) With a probability of $1 / 3$ not to lose anything, and with a probability of $2 / 3$ to lose everything.

As you can see, the conditions for managers in terms of losses and profits are the same, with a difference only in the formulations. That is, in principle, there should be no difference in making an investment decision. However, according to the results of the experiment, 63 per cent of managers in the condition of profits chose a guaranteed profit, but in the situation of the realisation of losses assumed the risk (75 per cent).

2) The second experiment was intended to reveal the features of decision making in situations where the magnitude of profits or losses is greater. And again, the same tendency was observed as in the previous experiment, in terms of profits about 78 per cent avoid risk, in terms of losses the same 72-77 per cent assume this risk. There was again asymmetry of risk.

3) In the third experiment, the goal was to find out how the respondents react to risk, if they are given a different formulation of the problem, in terms of costs and costs. The appearance of this experiment is due to the desire to find out how much the manager links the costs with the profit from them. If he equates them to losses, then according to previous survey data, we can expect to assume the risk. If, on the contrary, conservatism regarding risk should be expected. 
Managers were divided into two groups: one was proposed the wording in terms of profits, the other - in costs. Profitable wording narrated about product $\mathrm{A}$, which is in steady demand in the market, and which with a probability of 100 per cent will bring 420 thousand dollars in its production. There is also a product $\mathrm{B}$, which with a probability of 75 per cent will bring 520 thousand dollars, and 25 per cent - nothing.

The wording in terms of costs offered respondents the successful completion of the project with any choice, but in the first case it was necessary to spend an additional 420 thousand dollars to complete the project, and another with a probability of 75 per cent would require an even higher amount -570 thousand, but at the same time 25 per cent of cases no additional cost is required. Again, we see the symmetry of the construction of the problem with the difference of formulations. According to the results of the experiment, 88.2 per cent were avoided in terms of risk profits, and 62 per cent in terms of costs.

Contrary to the results of the first two experiments, in unprofitable terminology, the percentage of risk managers is much lower. Costs reduce the financial result from the investment activity of the manager. But, since the experiment clearly states that the result will be positive in any case, the respondents choose the risk-free option. In this particular case, risk avoidance is excessive. Therefore, risk-taking by managers is demonstrated when the probabilities of losses and gains from the adoption of any investment policy are formulated and mathematically calculated.

4) In the fourth experiment, the task was to choose one of two investment opportunities, and both in terms of profits and in terms of costs, the net profit, in any case, was equal to 325 thousand dollars. Profitable wording was slightly modified and sounded like investment returns, and accordingly changed the wording in terms of costs.

In terms of profits: there is a product $\mathrm{A}$, which is in constant demand, and which will bring 575 thousand dollars in the case of the choice of its production. There is also commodity $\mathrm{B}$, which has recently appeared on the market and the boundaries of the demand for it have not yet been precisely defined. However, after marketing research, it turned out that with a probability of 70 per cent in its production, you can get 665 thousand dollars, or with a probability of 30 per cent -365 thousand dollars. Both those and other options demand additional investments at a rate of 250 thousand dollars.
In terms of damages, as usual, identical conditions were proposed, otherwise formulated. It was said that with any choice, the project will be successful and will bring 575 , etc., the difference is only in the volume of funds required for additional investments. In the first variant, another 250 thousand dollars must be spent on the completion of the project, in the second with a probability of 70 per cent -160 thousand dollars, 30 per cent -460 , etc. Again, the same conditions cause imbalances in the investment decisions of financial managers. In terms of profits, 21.6 per cent took the risk, 78.4 per cent avoided. Respectively, in terms of losses -38.2 per cent and 61.8 per cent. As you can see, most investors chose to avoid risk, that is, in the wording of profits, to get a guaranteed profit, and in the case of costs, it is guaranteed not to spend more.

5) In the fifth experiment, researchers still put respondents in the conditions for the realisation of profits and costs. In the formulation of profits, the terms were set in such a way that it is possible to choose between two alternatives, for which with a 70 per cent probability there will be a high level of market demand and 30 per cent a low one. The difference between the projects is only in absolute values of the profits that the manager will receive. In the case of high demand for the goods, he makes a profit of 465 thousand dollars, but if the demand for the goods is small, then their size will be 155 thousand dollars. Alternative commodity B has a less profitable ability depending on market conditions. With high demand, the manager receives 384 thousand dollars, with low -344 thousand dollars. The deviation of the first alternative is higher and much more to be a representative for identifying a disposition to risk. The choice of the manager of the second option is pure risk avoidance.

Managers in terms of the implementation of losses were requested, at the request of state regulatory authorities, to consider two options for recycling, which are produced by the company manager. The first option implies a 70 per cent chance that it will take 465 thousand dollars; 30 per cent -155 thousand dollars. Alternative B offers a 70 per cent chance of a cost of 384 etc., 30 per cent -344 etc. As in all previous experiments, the conditions are identical, and the difference is expressed only in the formulation.

According to the results of the experiment, in terms of profits, 86.5 per cent of respondents 
avoided risk, accepted -13.5 per cent. In terms of costs, the choice of respondents was divided approximately equally, accepted the risk of 51.4 per cent, chose to avoid, 48.6 per cent.

For the first time during the five studies, the share of investors who take over and who refuse to take risks is approximately equal in terms of losses. However, this is because the losses are encoded in the form of the requirement of government agencies. In a normal situation, it is difficult to expect large profits from the recycling of your waste.

It is real, to a certain extent, representative data obtained from top managers of management companies. These data, in the same way, can show us the degree of the irrationality of investment activity of funds in the USA, empiricism that cannot be interpreted ambiguously because the research conditions for managers were given the simplest ones. Asymmetry in decision making is apparent, and it can be said with absolute certainty that having, at least, approximately similar alternatives in a real situation, the financial result from the investment decision would be even worse, because, in addition to individual behavioural deviations, noise information is added, erroneously interpreted by the manager because of its uselessness.

In fact, the mechanism of transferring funds to trust management, their multiplication, and the management of funds in the management company in any American, Russian (Russian in particular) and any other market is entangled in a strong network of irrationality or rather a cognitive irrationality. Let us start with the clients of mutual funds. What is the potential customer guided by when choosing the right fund? The ratio of risk/return, performance, recommendation, reputation. Of all this spectrum of factors, the first is more or less determining. Recommendations and advice are not any reliable information, because they come from a person subject to deviations and biased judgments to the same extent as the client. Information on performance indicators in various sources sometimes differs significantly, and therefore they are de facto nothing more than noise information, suitable only for compiling the most generalised picture of the foundation's activities. This behaviour has nothing to do with rational investment. Yes, and managers of funds of any market due to the nature of the activities are very susceptible to the influence of cognitive deviations. There are seven main problems of investing in various funds:
1) Forecasting. There is a tremendous amount of evidence that it is impossible to accurately predict any outcome of a process that is remote in time. And despite this, the market is fed up with all sorts of forecasts, analysts, and other unreliable information.

The reason for this lies in many factors, among which are excessive self-righteousness, excessive optimism at certain stages of the financial market. Forecasting is now one of the foundations of financial activity, without which practice cannot be imagined. It turns out that despite the fact that the overwhelming majority of market participants are mistaken in their forecasts due to both the system's inability to determine the price of an asset in the most accurate way in the future, and due to the imperfection of the methodology they use, it's still everyday mass media on financial markets are filled with regular attempts to predict the outcome of any process. It may seem meaningless. In no case should we forget that the forecast is noise, no more than someone's personal opinion on what is happening, suitable only for familiarisation, the formation of his own opinion, and not for copying and applying in his investment activity.

Figures 7 and 8 clearly show the quality level of analysts' forecasts for values of different nature. The first graph shows the forecasts of experts regarding inflation using the GDP deflator. The second graph shows the projections of the 10-year paper yield. It means that the respondents could not guess not only the level of the yield of the paper but also the direction of movement of this yield. In particular, 55 per cent of the forecasts for increasing profitability were differently directed with real movement, that is, in 55 per cent of cases, for a particular moment, the upward forecast coincided with a downward movement of paper.

If it is difficult to predict the movement of any particular paper, even using the entire array of available information on it, it is logical to assume that the movement of an index will be easier to predict. Fig. 9 shows how this hypothesis is true. The S\&P500 index on the graph is correlated with forecasts for its movement. Experts believe that the retrospective data is well tolerated for the future, as a result of which such a gap between the actual movement of the index and forecasts for two years is obtained.

As one of the main factors influencing the forecasting process, one can identify excessive self- 
confidence. Figure 10 illustrates the results of a survey in which students and professionals associated with the stock market were asked to choose a paper in which the respondent is confident, and which, in his opinion, will grow over the next three months. As can be seen, the share of students who have guessed such papers is significantly higher than the share of stock market professionals. It follows from this that market experience is not always a guarantee of good forecast quality, and the direction of movement of securities is not as apparent as it may seem.

2) The illusion of knowledge. The financial market is always dominated by the desire to get more and more information. In scientific literature, this phenomenon is called gluttony. It is exceptionally widely believed that possessing a large volume of information allows one to be always ahead of the market and to show positive results. Of course, this is the case; an uninformed participant is in any case, less effective than an informed participant. But do not overestimate the value of owning a variety of information. It can be differentiated by its quality. Yes, and its functionality is also in question. Very often, instead of adjusting the investment decision, the additional information only increases the investor's confidence that he is right. Therefore, the principle "the more, the better" in this case is not applicable.

Figures 11 and 12 reflect the results of a study on the effect of the amount of information on research participants. The purpose of the experiment was to identify how accurately a professional psychologist can determine a person's behaviour, his character, by periodical portions of information about his life, habits, and so on.

At first glance, there is no connection with the financial sphere. However, returning to the results of the study, it can be noted that as the amount of information available to psychologists increases, the quality of their assumptions does not increase, that is, they still make wrong conclusions, but with each stage and with each new information their confidence is correct, it is getting stronger. Fig. 12 shows those who changed his/her opinion after receiving new information about the object of observation. The tendency to increase self-righteousness is clearly expressed.

This experiment confirms the fact that additional amounts of information are interpreted not as information to the consideration or revision of

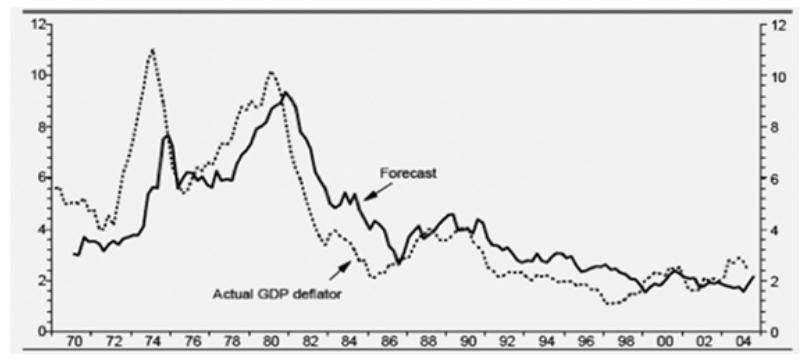

Fig. 7. US GDP deflator and forecasts.

Source: Bloomberg.com. (2019). About US Real GDP. Available at: https://www.bloomberg.com/quote/EHGDUSY: IND.

Accessed 5 March 2019.

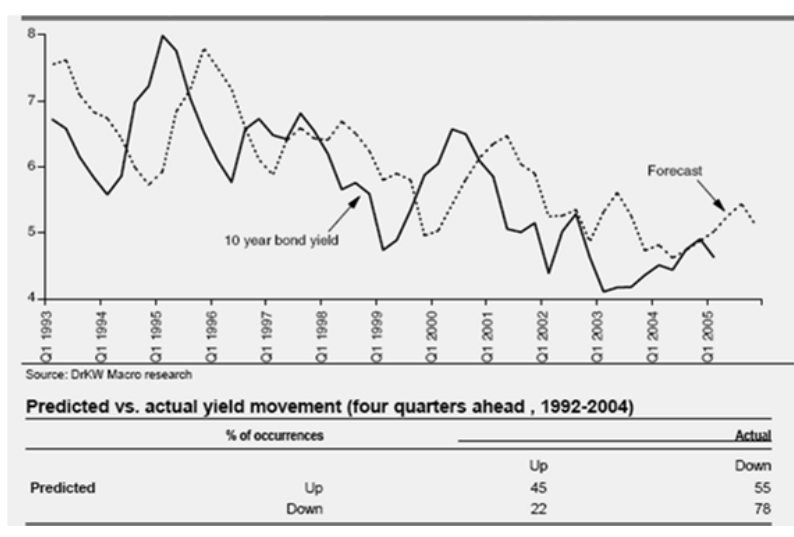

Fig. 8. Consensus one year ahead bond yield forecasts and reality (per cent).

Source: Russo \& Schoemaker, 1989, p. 97.

their position regarding any phenomenon, but as a means of confirming it. The ability of large amounts of information of different quality to influence investment decisions is underestimated and is not sufficiently taken into account.

3) All sorts of meetings, roadshows. Many companies pay great attention to organising meetings with potential investors. However, such meetings are unlikely to be a real investment burden for the investor. There are certain issues that need to be taken into account for meetings with company representatives to bring real value. First, as mentioned earlier, more information does not mean better performance. Secondly, managers are also subject to cognitive errors, and their point of view is almost always excessively optimistic about the nature of their activities and the results that can be obtained from investing. Thirdly, for an investor who is still hesitant about any decision, the information that will be in line with his desires is dominant. Fourthly, according to research data, after such meetings, many investors admit that the representative type of the company's management played a significant role in the investor's decision 
making. It is a non-financial aspect that inclines many market participants towards a solution that might not be the best one on the market. And fifth, there is always the risk of receiving inaccurate information, altered, or in any other way adjusted to increase attractiveness. And not still the investor has the opportunity to check the quality of the information received.

In confirmation of the above, it is advisable to bring these studies, which is carried out every quarter among the 500 largest US companies. Their CFOs are asked a lot of questions, one of which is: "Assess the potential of the economy and your company for the next quarter". In all cases, managers evaluated the potential of their company above the market, which indicates a high degree of confidence in their capabilities; that they can all replay the market (see Fig. 13). From this follows the conclusion that the managers of the reassessment of their management skills and financial results of the company.

4) Self revaluation. The factor is related mainly to the previous one; his/her self revaluation is more "elongated" in the time interval. Successes on any lengthy period can lead to the fact that the methodology of activity can be simplified, superoptimism and excessive trust in the manager's ability to assess and process market information, confidence in the ability to 'read' the market, outpace it will appear. To buy at the bottom and sell at the top for a long time is impossible, even having an idea about the peculiarities of the "crowd" behaviour, that is, studying behavioural finances.

5) Short term and replay. Since many operators confuse information with noise, and at the same time try to get ahead of the market, excessive trading activity occurs. In turn, it leads to a reduction in the holding period of the paper in the portfolio. On the New York Stock Exchange, for example, the average term for holding a paper in a portfolio is $8-9$ months. That is, the result of such a paper is a function of the change in prices for it during this period, and this period may not be representative of the previous or subsequent ones. Such financial activities are more speculative than investment.

Figures 14 and 15 show how much the holding period of securities in US mutual funds has changed over the past 90 years. If you pay attention to the $50-60 \mathrm{~s}$, you can see that the funds operated as long as possible at that time, and the NYSE papers

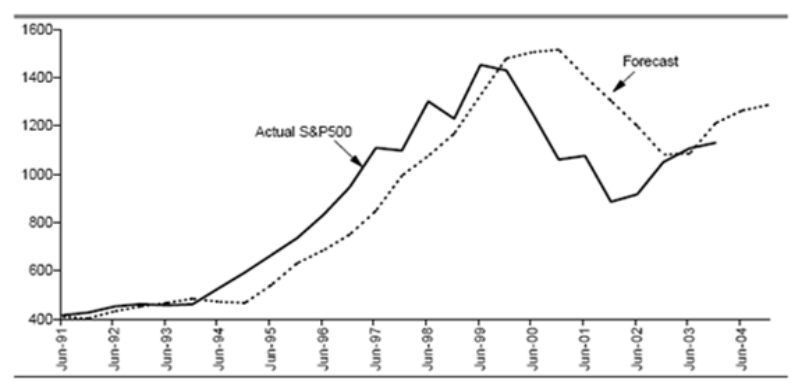

Fig. 9. S\&P500 Index Forecast.

Source: Russo \& Schoemaker, 1989, p. 97.

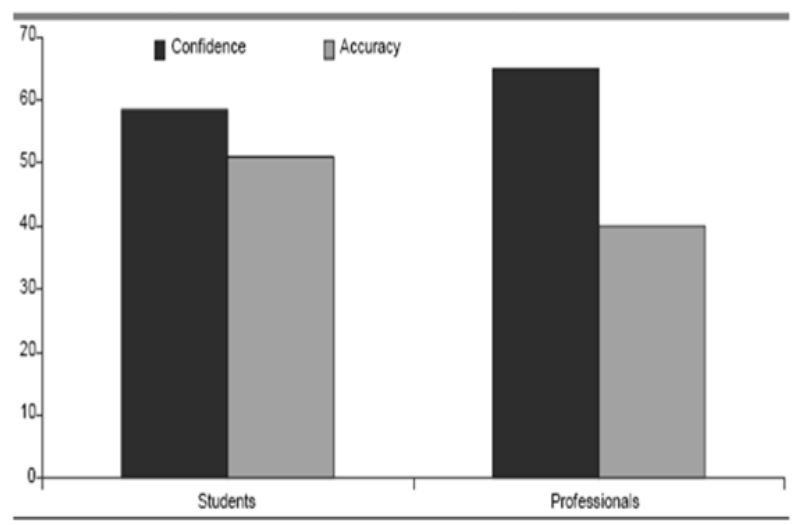

Fig. 10. Average Accuracy and confidence considering stock selection (\%).

Source: https://www.drkwresearch.com. Accessed 8 Apr. 2019.

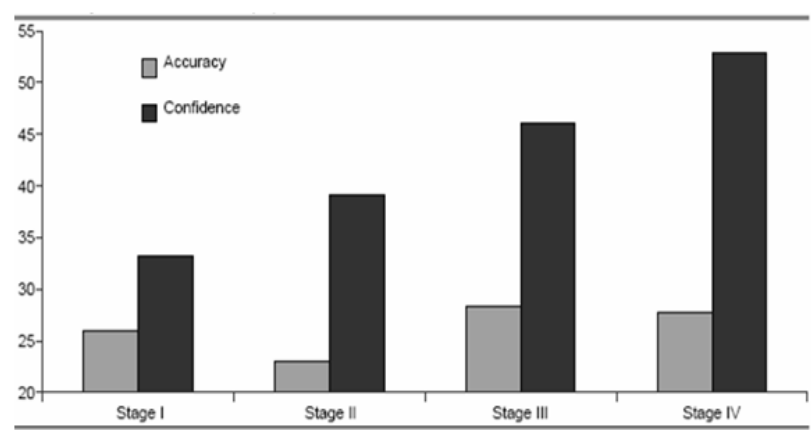

Fig. 11. Increase confidence as the volume of available information increases.

Source: Slovic, 1991.

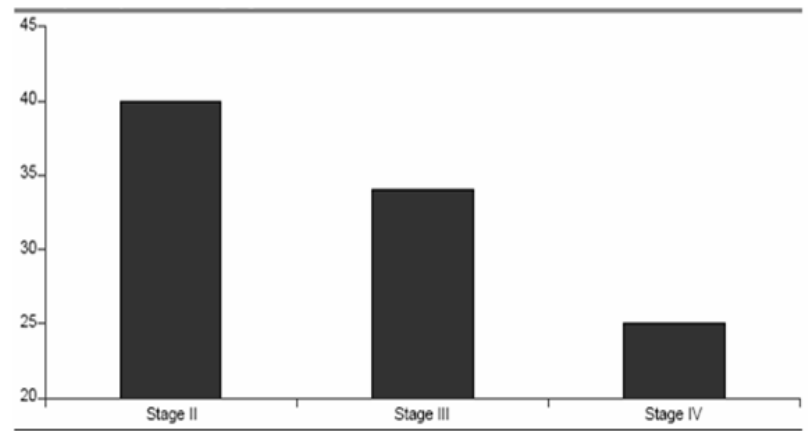

Fig. 12. The share of experts who change their opinion each round.

Source: Slovic, 1991. 
were held for seven to eight years on average, as opposed to the current annual similar indicators.

6) Trustfulness. Associated with previous problems, this one is also crucial. It is necessary initially to be sceptical about the received information, changing its opinion in relation to it as other information comes from other sources confirming it. Many investors believe that they can accurately distinguish reliable information from poor-quality information. However, there are no grounds for this, and to differentiate between incorrect information and correct information, you need to have a particular array of information that will allow you to decide on the reliability of the information received. Associated with previous problems, this one is also crucial. It is necessary initially to be sceptical about the received information, changing its opinion in relation to it as other information comes from other sources confirming it. Many investors believe that they can accurately distinguish reliable information from poor-quality information. However, there are no grounds for this, and to distinguish between incorrect information and correct information, you need to have a particular array of information that will allow you to decide on the reliability of the information received.

7) Group judgment. This problem is hidden until the results of the application of group judgments in the financial sphere become clear. There is an opinion that the decision taken in the group differs in the qualitatively better side from the individual and allows achieving better results. It is a much deeper problem than it seems. Of course, with zero investor awareness, a group decision is definitely better than its unreasonable individual one. However, if the operator has some experience in working in the market, and his ability to receive information quickly and without cost is high, then the need for group actions should be carefully assessed. One would expect the group to level individual cognitive delusions, but, instead, the group only reinforces them. Gathering in a group, investors have already predetermined the task to come to any decision along the path of least resistance. The group reduces the variability of opinions. On the way to making an investment decision, the group always becomes a victim of the "anchoring effect", that is, any information that intersects in any way with their vision, they begin to interpret as confirming their predictions.

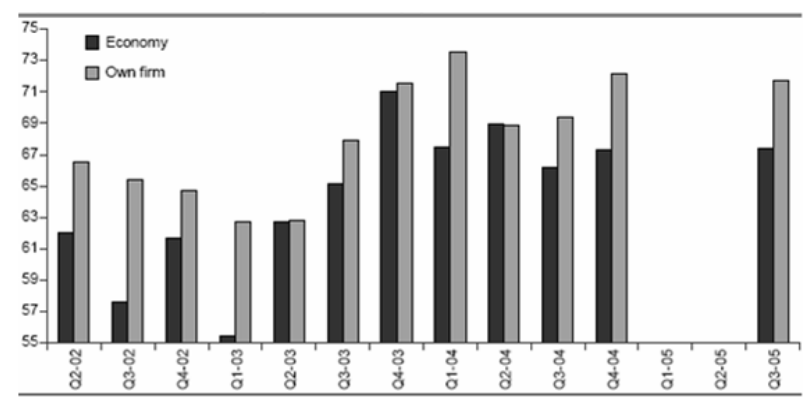

Fig. 13. Optimism over the economy and own firm (\%).

Source: Cfosurvey.org. (2019). Duke CFO Global Business Outlook. Available at: http://www.cfosurvey.org. Accessed 8 April 2019.

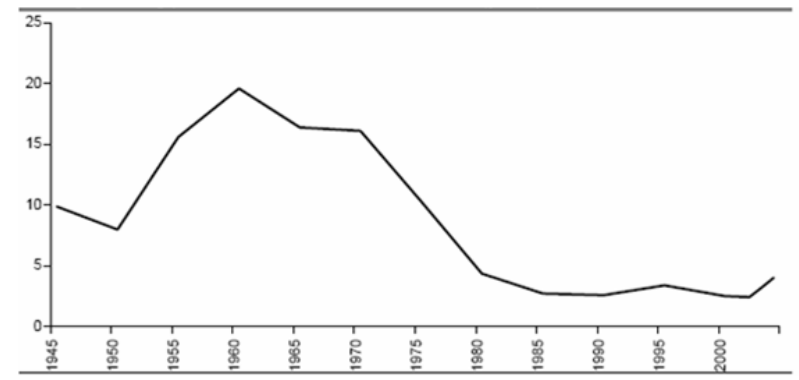

Fig. 14. Average holding period of US mutual fund investors (years).

Source: Bogle, 2005, p. 37.

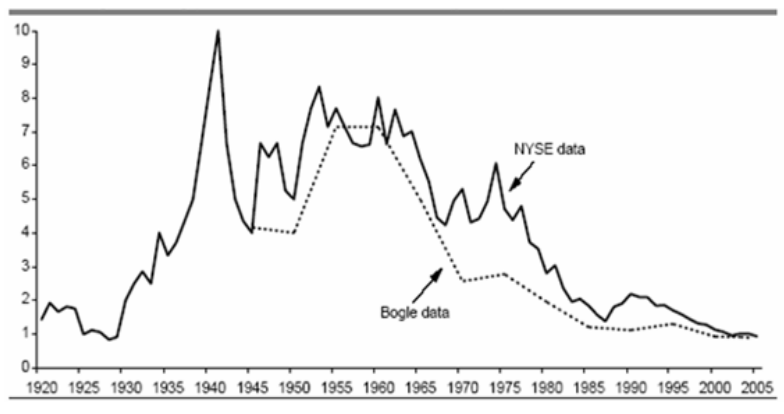

Fig 15. The average holding period of NYSE listed stocks (years).

Source: Graham, Harvey, \& Rajgopal, 2004.

\section{Impact of the Theory and Methods of Behavioural Economics and Finance in Practice}

\subsection{Use of behavioural tools in the process of making financial decisions}

To understand the essence of the findings of Shiller, you must first think about what determines the price of shares. Suppose a particular fund decided to buy a block of shares and keep them forever. In other words, these shares are not going to be resold, and therefore the fund can receive profit from these securities only in the form of dividends after some time. The value of the shares must be equal to the "current value" of 
all dividends that the fund will receive in the future after the purchase of shares, i.e. this is the amount in which the cash flow is estimated after the necessary adjustments, taking into account that the money tomorrow will cost less than the money today. Although because we do not know precisely how much profit in dividends a certain block of shares will bring, the share price is only a forecast, reflecting market expectations regarding the present value of all future dividend payments.

A rational forecast has an outstanding property: as it should be on stock quotes, the forecast cannot fluctuate more than the object of the forecast. Robert Shiller, now a professor at Yale University, published the results of his research in 1981.

Shiller got his results when he applied this principle to the stock market. He collected data on stock quotes and dividends since 1871 . Then, for each year after 1871, he calculated what he called the "expropriational" forecast for the flow of future dividends that would go to someone who wanted to buy a portfolio of all the securities that existed at that time. To do this, he took data on the number of dividends that were paid and discounted them for the required year. Having corrected for the well-established trend, according to which, over a long period, quotes show growth, Schiller found that the present value of dividends was very stable. But stock prices, which we must interpret as attempts to predict the current cost of dividends, fluctuated very strongly.

A practically flat line on the chart shows the dynamics of changes in the current value of dividends, while the bouncing line reflects the real value of the shares, both of which were corrected to eliminate the long-term effect of the increase in value over the long term (see Fig. 16).

In his article, Shiller asked himself the question "Do stock prices fluctuate enough to explain their subsequent changes in dividends?" Based on Figure 16 , the answer to this question is positive. The results of Schiller provoked a strong reaction in financial circles and published articles. Some authors criticised the method of Schiller and his conclusions.

On Monday, October 19, 1987, Robert Shiller's idea that financial markets were too volatile was confirmed. On that day, quotes dropped significantly worldwide. It all started in Hong Kong and then expanded to the West, as the exchanges opened in Europe and then in the USA. In New York, stocks collapsed by more than 20 per cent. Monday, October 19, is of critical importance because, on this day, nothing unusual happened in the field of finance or any other. No war has begun, no political leader has been killed, and nothing remarkable has happened. However, stocks fell around the world, and no one could say why. Price fluctuations continued for the next few days. In America, the S\&P500 index of large companies scored 5.3 per cent already on Tuesday, jumped another 9.1 per cent on Wednesday and again fell by 8.3 per cent on Monday, the 26th. In the rational world, quotes change only as a result of the reaction to the news, and during that week the only news was that prices "jumped".

If quotes are so susceptible to volatility, then they are, to some extent 'wrong'. It is difficult to argue that the price is at the close of trading on Thursday, October 15, and the price at the close of trading next Monday (which is already 25 per cent lower) can be rational indicators of true value, given the lack of news. Thus, the idea that the market price is always correct is refuted.

When Shiller wrote his first article, he did not think to give explanations in terms of the behavioural approach. He merely communicated facts that are difficult to explain rationally. However, in 1984 he wrote the article "Stock Prices and Social Dynamics", in which the idea was developed that social phenomena can influence stock quotes just as they do in the fashion world.

In the hypothesis of an effective market, apart from the principle that price is always correct; there is also the principle that the market cannot be replayed. Schiller's research also has a bearing on this principle and refutes it.

To understand the reason, it is necessary to pay attention to some of the conclusions obtained from studies of value investment. Valuable stocks, where even securities with extremely low $\mathrm{P} / \mathrm{E}$ ratios can be, show a return that exceeds the market average. You can also calculate the $\mathrm{P} / \mathrm{E}$ ratio for the entire market. The question arises: does the same principle work, that is, is it possible to outplay the market if you buy stocks when they are relatively cheap and wait until they become relatively expensive?

To solve this issue, Shiller preferred to use the method, which consisted in dividing the index of stock quotes (such as S\&P500) by the average yield over the past ten years. He prefers this method of retrospective monitoring of profitability because it allows smoothing the temporal fluctuations that occur during the business cycle. The graph of the obtained coefficient is depicted in Fig. 17. 
Evaluating the events in hindsight from the chart, you can see what the investor's strategy should be. It is important to note that when the market deviates from the historical trend, in the end, it returns to the average. In the 1970s, stock prices were fairly low but eventually recovered, and by the end of the 1990s, prices seemed rather high, but ultimately, they fell. Thus, in the long-term dynamics of the P/E index, which Shiller demonstrated, there is indeed some predictive power. However, this predictive power is not very accurate.

Was Shiller's warning correct, or was he wrong? Since his warning was made four years before the market swooped down, we can say that he was mistaken for a long time before being right. This inaccuracy means that the long-term dynamics of the price/earnings ratio cannot serve as a full guarantee of profitable deals. Anyone who would follow Shiller's advice in 1996 and bet on a falling market would have suffered a loss before there was a chance for a profitable deal.

The same conclusion is correct for the real estate market. The work that Robert Shiller did with Karl Case is now the widely known Case-Shiller Index of property prices. Before this index, real estate price indicators were not very reliable, since the set of houses sold in a particular month could be very different, distorting the average. At the core of the Case-Shiller Index are recurring sales of the same house, to control the type of house and its location.

Long-term growth in property prices (see Fig. 18), where real estate price data collected by the government before 2000 is used, after which CaseShiller data became available, so both data sources are used here.

The graph shows a moderate increase in housing prices throughout the study period until the 1990s and after that a sharp rise. Besides, after a long period during which the index of the ratio of the price of buying a home to the rental price of identical housing fluctuated around the 20:1 mark, housing prices differed sharply from this long-term trend. Having this data before his eyes, Shiller warned about the danger of a real estate price bubble, which eventually happened. However, at that time no one could be sure whether it was a bubble, or something changed in the economy, as a result of which much higher purchase price/ rental price ratios were established as a new norm.

It should be clarified that the inaccuracy of these passes does not mean that they are useless. When

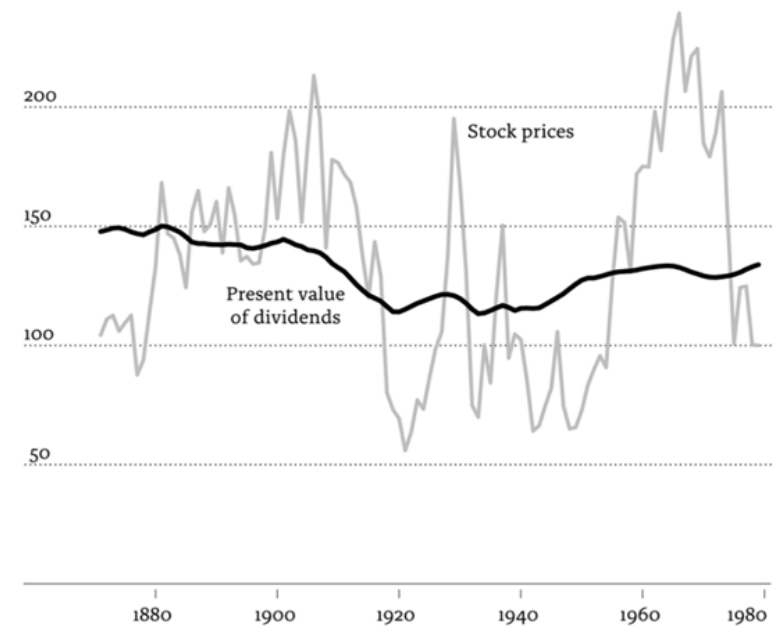

Fig. 16. Are Stock Markets Too Volatile?

Source: Shiller, 1980, p. 292.

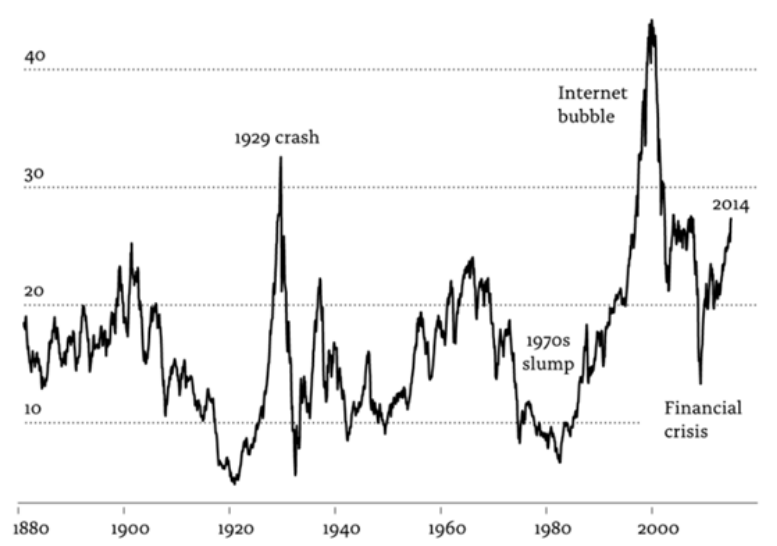

Fig. 17. Long-Term Stock Market Price/Earnings Ratios.

Source: Home Page of Robert J. Shiller. Available at: http://www.econ.yale.edu/ shiller. Accessed 9 May 2019.

prices strongly deviate from the historical level, it does not matter in which direction the predicted value is hidden in these signals. The more the price deviates from the historical level, the more seriously these signals should be perceived. Investors should be cautious in pouring money into a market that signals of overheating, but investors should also not expect a quick profit, relying on an accurate forecast of market dynamics. It is much easier to determine the presence in the price bubble than to say when it will burst. Investors are rarely able to earn by calculating the time changes in market dynamics.

\subsection{A mathematical approach to behavioural decision-making}

A model of investor sentiment will be considered to explain the problems of the stock market. This model is centred on beliefs. 
There are two stable pricing regularities: a weak price response to a single news item, for example, the earnings of stock issuers, and an overreaction to a series of specific news. In the model below, the reaction is weak, if the expected return after the good news should exceed the expected return after the bad news, and excessive, if the expected return after a series of good news is less than the expected yield after a series of bad news.

Some problems in the stock market are the result of systematic errors committed by investors during the use of public information to form expectations for future cash flows. Their model takes into account two heuristics triggered by updating the original beliefs: conservatism (the tendency to underestimate the new information) and a special version of representativeness, called the "law of small numbers" (the belief that even small samples reflect the properties of the maternal population).

When a company announces unexpectedly good revenues, conservatism suggests that investors react sluggishly; the stock price and subsequent returns will rise slightly. After a series of announcements of good earnings, the representativeness will cause investors to over-react, and the stock price will become too high compared to the fundamental value.

The reason is that after many periods of good revenue, the law of small numbers tends investors to think (believe) that this is a company with a particularly rapid increase in revenue. Therefore, they forecast the high revenue in the future. In the end, the company cannot be average. According to the law of small numbers, if a company is average, then its revenue would be average even in short samples. Once the stock price is too high, the subsequent return is too low on average, and in the long run, reversals (price changes in the opposite direction) and the effect of scaled price ratios (scaled price ratios - rate to profit, book value to market and other price-to-cash flow ratios. Stocks with an underestimate after scaling tend to show increased returns in the future) is expected.

To reflect these ideas mathematically, we developed a model with a representative and risk-neutral investor, where revenue dynamics follow a random walk process. Investors, however, do not use such a process to predict revenue. They think that at any time the revenue is generated by one of two modes:

1) Revenue returns to its average, normal value, more than in reality; good news will change badly;

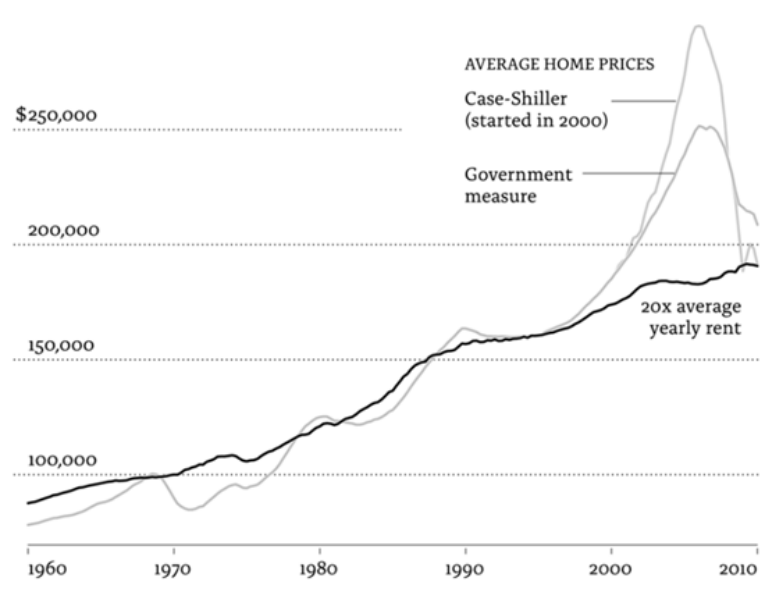

Fig. 18. Long-term dynamics of housing prices and rental prices in the US.

Source: Klyuev, 2008, p. 20.

2) Revenue has a more stable trend than in reality; good (bad) news will be followed by another good (bad) news.

The investor believes that the revenue generated in this way varies exogenously with time and sees its task in determining which mode is generating revenue now. This approach offers one way to simulate deviations when updating beliefs.

A model with trend captures the effect of representativeness, allowing investors to give the trend more weight than they should. Conservatism means that people may underestimate the latest news about good revenue in the light of past beliefs. In other words, when the news is positive, they begin to act, assuming that in the next period the news will be at least partially negative, that is, they believe in the return mode.

We turn to the consequences for pricing process. Since the model participant is a representative investor, the share price is simply the investor's expected inflow (in his pocket) of discounted earnings for future periods:

$$
P_{t}=E_{t}\left\{\frac{N_{t+1}}{1+\delta}+\frac{N_{t+2}}{(1+\delta)^{2}}+\ldots\right\},
$$
where $N$ is revenue and $\frac{1}{1+\delta}$ is a discounting
factor.

In this case, the expectations are the expectations of the investor who is unaware that the dynamics of the proceeds follow the random walk process. Otherwise, because in the case of the random walk process $E_{t}=\left(N_{t+j}\right)=N_{t}$, the price would be equal to $N_{t} / \delta$.

In the model used, the price deviates from the true value of the paper, since the investor uses 
not the random walk model, but a combination of the aforementioned modes to predict revenue. In this case, the price is satisfied by the following expression:

$$
P_{t}=N_{t} / \delta+y_{t}\left(p_{1}-p_{2} \pi_{t}\right),
$$

where $p_{1}$ and $p_{2}$ are constants and depended on $\pi_{\mathrm{H}}, \pi_{\mathrm{L}}, \lambda_{1}$ and $\lambda_{2} ; \pi_{\mathrm{H}}, \pi_{\mathrm{L}}-$ probabilities of changes in revenue for the better $(H)$ and worst $(L) ; \lambda_{1}$ and $\lambda_{2}-$ probability of changing one mode to another.

Interpretation is simple; $N_{t} / \delta$ is the price in the case of using the random walk model to predict revenue; $y_{t}\left(p_{1}-p_{2} \pi_{t}\right)-$ deviation from the fundamental value.

Firstly, if the price $P_{t}$ responds poorly to the news on revenue on average, the constant cannot be too large relative to the constant $p_{2} \cdot y_{t}$ is good news. A weak reaction means that on average a deviation $y_{t}\left(p_{1}-p_{2} \pi_{t}\right)$ must be negative. If $\pi_{a v g}$ is the average probability, the above implies that $p_{1}<p_{2} \pi_{\text {avg }}$. In this sense $p_{1}$ cannot be too large in relation to $p_{2}$.

Secondly, if $P_{t}$ responds beyond measure to a series of equivalent news, $p_{1}$ cannot be too small in relation to $p_{2}$. Let the investor receive a series of good news. Excessive reaction means that the price must be higher than the fundamental value. Moreover, after a series of equivalent news $\pi_{t}$ is usually low $(L)$, indicating a low weight of the first model (return to average) and a high weight of the second model with a trend. $\pi_{\text {low }}$ is a typical low value of $\pi_{t}$, then overreaction requires $y_{t}\left(p_{1}-p_{2} \pi_{t}\right)$ to be positive or $p_{1}>p_{2} \pi_{\text {low }}$. From the first and second paragraph the following equality follows:

$$
p_{2} \pi_{\text {low }}<p_{1}<p_{2} \pi_{\text {avg }}
$$

This model shows that the interaction of the formation of investor beliefs and the true revenue model can explain two different empirical regularities - a weak reaction to certain news and an overreaction to a series of equal news. The model is based on psychological evidence and at very different values of its parameters generates the reaction of both types.

The model that will be given below describes the factors that influence the decision-making process of investors. In a paper written by Guney and Hussain (2007) about measuring equity mispricing, financial constraints, market timing and targeting behaviour of companies, investigated market timing theory for UK based firms. They proposed that managers increase debt (equity) issues during periods of undervaluation (overvaluation).

Managers, thus, seem to time issues strategically out of necessity rather than being able to do so. Both the timing of issues and repurchasing are influenced by reaching target leverage. The evidence suggests that managers are clearly aware of the cost of being off-target and weigh this against the benefit gained from timing the market.

Their initial sample comprises all U.K. firms available from 1984 to 2008 . He also excludes financial firms. The final sample includes of 11,201 firm-year observations.

Variables used in this model are same book leverage (BL), the net debt issues ( $\Delta \mathrm{dbl})$, the net equity issues $(\Delta \mathrm{e})$, SIZE, Tangibility of assets (TANG), R\&D and CAPEX are proxies for growth options defined as research and development expenses scaled by total assets, and capital expenditure divided by total assets, respectively. Profitability (PROF) is the earnings before interest, taxes and depreciation over total assets.

The authors expand the model used by ShyamSunder and Myers (1999) and include a measure of valuation to proxy for timing. The model used regresses the net debt issued on the financing deficit and is defined as $D E F_{\text {it }}$ for firm $i$ in year $t$ as follows: $D I V_{i t}$ is cash dividends, $I_{i t}$ is net investments, $\Delta W_{i t}$ is net working capital, and $C_{i t}$ is cash flow after interest and taxes. The sum is identical to net debt issued $\left(\Delta d_{i t}\right)$ and net equity issued $\left(\Delta e_{i t}\right)$.

$$
D E F_{i t}=D I V_{i t}+I_{i t}+\Delta W_{i t}-C_{i t}=\Delta d_{i t}+\Delta e_{i t} .
$$

The authors measure mispricing with the ratio of intrinsic value (IV) to the current market

$$
\begin{gathered}
V_{\text {equity }}=\sum_{t=1}^{\infty} \frac{F C F E_{t}}{\left(1+r_{e}\right)^{t}} \\
V_{\text {equity }}=\sum_{t=1}^{\infty} \frac{F C F E_{t}}{\left(1+r_{e}\right)^{t}}=\sum_{t=1}^{N} \frac{F C F E_{t}}{1+r_{e}^{t}}+\frac{\text { Terminal Value }}{\left(1+r_{e}\right)^{N}},
\end{gathered}
$$

price $(M P)$. Intrinsic value is measured as follows:

$$
\text { Terminal Value }=\frac{F C F E_{N}(1+g)}{\left(r_{e}-g\right)} .
$$


Where $g$ is the long-term FCFE growth. Given that FCFE occurs throughout the year, we make adjustments as follows:

$$
V_{\text {equity }}=\left[\sum_{t=1}^{N} \frac{F C F E_{t}}{\left(1+r_{e}\right)^{t}}\right]\left(1+r_{e}\right)^{0.5}=\left[\frac{F C F E(1+g)}{1+r_{e}^{t}}\right]\left(1+r_{e}\right)^{0.5} \text {. }
$$

$F C F E_{t}$ is free cash flow to equity at time $t$, and $r_{e}$ is the cost of equity. FCFE is the sum of net income plus depreciation minus change in non-cash working capital minus capital expenditure minus principal repayments of debt capital plus new debt issued.

$$
\text { Misvaluation }=\frac{I V_{i t}}{M P_{i t}}
$$

The final model is:

$$
\begin{gathered}
\Delta d b l_{i t}=\alpha+\beta_{1} D E F_{i t}+\beta_{2} U N D V D_{i t}+ \\
+\beta_{3}(U N D V D \times D E F)_{i t}+\varepsilon_{i t} .
\end{gathered}
$$

Thus, this model shows a strong dependence of company valuation on risks. At the same time, investors look at the above factors and make decisions about whether to invest in a company or not.

Company valuation also depends on growth factors. The higher the growth of the company, the more attractive it looks to the investor, although this is not always the best option, since the growth of the company does not always reflect its stability, and the growth factors may be random (for example, inflation). In this case, the effect of an overly acute reaction can also occur investors have made an overly optimistic outlook on the future growth of some companies, but at the same time, they too low the rest. If so, then the subsequent investment of money by investors in 'good' companies and the withdrawal of money from 'bad' companies is a simple regression to the mean.

Companies that have demonstrated high returns for several years in a row acquire a reputation as a 'good' company and will continue to increase. On the other hand, companies that have been lagging in the past few years are labelled 'bad companies'. Thus, a stereotype is formed at the corporate level.

Indirect evidence of the overreaction of investors existed for a long time - in particular, this is a long-standing strategy of "investing in value" that Benjamin Graham was the first to practice.
Graham was a professional investor and professor at Columbia University. Graham is often called the progenitor of an investment strategy in value, the essence of which is to search for securities that are priced below their real long-term value. The trick is to know how to calculate them. One of the mechanisms for determining the high cost or cheapness of the securities proposed by Graham is to calculate the price/earnings ratio $(\mathrm{P} / \mathrm{E})$, where the price per share is divided by the annual yield per share. If this ratio is high, investors pay too much per dollar of profit, and, indirectly, a high ratio is an indicator of rapidly growing stock returns to justify the current high price. If profits do not grow as fast as expected, the stock price will fall. Accordingly, in the case of a low ratio of securities, the market predicts that profits will remain low or even decline even more. If the yield starts to grow or remains the same, the stock price will rise.

One study from Graham illustrates the effectiveness of his method (Graham, 1976, pp. 20-23). Since 1937, Graham took the shares of 30 companies in the Dow Jones index for industrial companies (several major American companies) and ranked them based on the P/E ratio. After that, he formed two portfolios - one of the stocks of 10 companies with the highest $\mathrm{P} / \mathrm{E}$ ratios, and the second of the stocks of 10 companies with the lowest $\mathrm{P} / \mathrm{E}$ ratios. The result showed that cheap securities yielded more income than securities from the expensive price group, while with a significant margin. For the period from 1937 to $1969, \$ 10,000$ invested in cheap securities rose in price to $\$ 66,900$, while the portfolio with expensive securities rose only to $\$ 25,300$. If the entire portfolio of 30 companies were acquired, the yield would be $\$ 44,000$. Although not explicitly, Graham essentially offered a behavioural explanation for this phenomenon.

Cheap securities were unpopular or non-preferred, while expensive securities were in demand and fashionable. If you act contrary to market trends, Graham argued, you can replay the market, although not always. He drew attention to the fact that his strategy of buying the cheapest Dow Jones companies for industrial companies would not have worked in the earlier period, from 1917 to 1933, and he warned that an underestimation resulting from an oversight or prejudice could last for an excessively long time, and the same applies to overpriced prices caused by excessive enthusiasm or artificial incentives. This advice would have been worthwhile to use during 
the technology bubble in the late 1990s, when the cost-investing strategy worked extremely poorly since most of the expensive securities of Internet companies continued to grow in value, leaving the boring value stocks far behind.

By the early 1980s, most financial economists considered the Graham approach obsolete. The simple strategy of buying cheap securities had an apparent discrepancy with the efficient market hypothesis, and Graham's methods could hardly be called modern. Data on the profitability of various companies were collected manually. Now researchers use digital databases with which they could conduct much more extensive research, and the results obtained by analysing a small number of companies in a relatively short period, as it was Graham, were no longer taken seriously.

It is not that everyone rejected Graham's assertion about the value of investments in value; instead, the point was that the efficient market theory of the 1970s argued that value investment could not work. But it worked. Later, Professor Sanjoy Basu published competent research on investing in value, the results of which fully confirmed the validity of the Graham strategy (Basu, 1983).

\subsection{Barriers to the development of a behavioural approach}

Having considered the theoretical and practical basis of behavioural finance, we can conclude that there is still a very long way to the effectiveness of markets and rationality of investors. The system of making profits is currently built precisely on numerical imbalances, which are evident to most market participants. Few people can recognise a quality investment alternative.

Behavioural finance is a new development, a lot of research is still underway, and there is a lot of work ahead in this area. However, the overwhelming majority of studies indicate the imperfection of the behavioural models of operators in the securities market and others, without putting forward specific measures on what needs to be done. Studies are indicative. In this regard, how useful can any innovative thought or theory in the financial market be, if it has no visible practical application? How to use the achievements in the field of behavioural finance, if the authors of the publications do not give specific instructions on specific measures to "beat the market" and extract increased profitability from their operations?
It is worth noting that very many market participants, mainly practitioners, do not have any idea at all about the existence of a behavioural approach to the activities in which they are engaged day after day. It is these operators, or rather the features of their investment activity, that are the subject of ongoing research in the field of financial psychology.

It cannot be said that the results of the research can somehow be "applied" or "used." After examining the most common market errors, the investor will have to do work to eliminate or minimise their own. The process is time-consuming, lengthy, and does not guarantee an increased financial result. It will be difficult for the operator to find out in numerical terms between the decision taken in the typical situation according to ordinary standards and when making a decision that takes into account possible behavioural deviations of the investor and with a more comprehensive methodology for analysing the effectiveness. The operator will only be confident that his decisions are based on fundamental factors that are effective in the long term. For a rational investor, it is not known how the market may behave in the future, yet the possibilities of analysis and forecasting are to a certain extent limited. Whereas irrational investors, for the most part, misuse the advancement of forecasts, operations with dubious information, and operate under the influence of many behavioural deviations that they are unaware of, or do not think about.

Several factors hinder the widespread and widespread knowledge of financial psychology. Generally, they can be grouped into macro-level factors and micro-level factors.

Because any direction is created to somehow influences the established order of things, this direction has to have all the required characteristics to ensure work within its framework. Behavioural finance is an element of the system that empirically denies the applicability of the theory of efficient markets with its initial assumptions about investor rationality and equal access to information for them.

Research in this area, as mentioned above, are indicative. Scientists, to reveal the systematic nature of any deviation, spend a lot of time and labour on collecting statistics, analysing, processing, and grouping it, to create the depth of research, and to draw some conclusion from the total amount of work done. As a rule, there is indeed a systemic deviation in the operators' investment activity, based on statistics, the reasons for the existence 
of this deviation are explained in principle, and further research continues on some related issue.

In the minimum number of publications you find any recommendations for the practical application of the results of the work done. This situation has developed for several reasons. First, initially, information about the presence of errors when making an investment decision does not carry any value. The specificity of the financial market is that someone wins, and someone loses. There is always an opportunity, a chance to make a profit without delving into the causes of their past failures and without drawing appropriate conclusions from them. For example, the widespread "Monte-Carlo Simulation" (Towards..., 2019), when an investor neglects the law of small numbers and makes decisions based on his feelings, without even trying to assess the probability of the desired event correctly, will be of little importance if he eventually "guesses" the outcome of the event.

The state of affairs could be different if scientists applied examples of their research to real-life practise to research. They explained how to counteract the influence of a particular effect, cited an approximate methodology or sequence of actions taken to avoid common deviations.

However, nothing like this happens. Assessing how much time (in some cases up to 10 years) scientists spend on analysing and identifying any example of irrationality, it is doubtful that an individual investor will be able to quickly find the optimal system for analysing the event of interest, adjust the process of evaluating and making an investment decision and firmly stick to it in the future, given the various variations and modifications of the situation.

Moreover, even many disparate mathematical substantiations of their research would not be enough to popularise and expand the applicability of the behavioural approach in financial markets. Works and mathematical methods should correlate with each other; you need to be able to take into account the influence of factors of one type on the investor's activities.

Thus, the conclusion suggests the following: for the behavioural approach to become widespread among market participants, it is not enough to observe the mistakes of investors from different years, even if they can be systematised and generalised, and based on which you can draw some conclusions with practical value. The behavioural approach needs to have a mathematical superstructure to the mathematical apparatus of the concept of an effective market.

Otherwise, unfortunately, the concept of "behavioural finance" serves as an additional source of knowledge for the investor, which should be specially noted, of an individual, and not of a legal one, for the reasons described above.

The next factor that has the most negative impact on the prevalence and use of this is the degree of publicity of works studying the behaviour of investors and their delusions. The range of sources through which publications reach readers, research and various analyses of market activity is limited even in the United States to just a few publications among which The Journal of Finance, Journal of Political Economy accounts for about 40 per cent of publications, with a large number of publications directly to behavioural Finance does not apply, but they are integrated into the system of cognitive knowledge due to the possibility of correlating research results in such publications with the psychology of investing. Moreover, the practice adopted by many publications, which consists in posting long-standing articles from the journal's numbers on the website of the publication, is not applicable. Articles for some time are in the paid access.

Naturally, such limited resources of information negatively affect the development of a behavioural approach in financial thought. The paper version of leading publications is difficult to get outside the USA and work in the periodical financial press, even in rare cases when the behavioural topic is touched upon, most often boils down to recommendations for more careful diversification of the portfolio and thinking about each investment decision. Due to the limited journal space, the work loses the depth of research and becomes a means of general development.

Therefore, at the current moment, to be able to study any publications on the topic, it is necessary that there exists a direct interest from the investor, his time spent searching for work in the original paper or electronic version. Other sources are not well suited to be an information resource in this area, due to the limited material in most sources.

There are a large number of investors and professional participants in the financial market whose interests, investment preferences and activity methodology differ significantly. It is so because these 
participants have different needs in the market, each in its way evaluates the quality of the paper, and everyone considers the optimal 'urgency' of the paper also differently.

The active type of an individual investor, for example, as previously noted, is characterised by a high rate of portfolio renewal. This particular investor considers this type of activity to be optimal, and he will also be on the market in the future, apart from emergencies, such as crises, most likely. But with a high rate of portfolio renewal, the investor plays on short-term fluctuations in the price of the instrument, where the fundamental characteristics of the paper may not appear. Accordingly, he can get either speculative profit or loss.

The relationship of this particular case with the development of behavioural finance, at first glance, is weak. However, if we recall any more or less significant work in the field of investor psychology, then it will become clear that all the studies that were conducted by scientists are long-term in nature. To identify any behavioural abnormalities, scientists usually needed time with statistical data of at least five years. How can an active investor apply the achievements of a behavioural approach to his high-intensity work in the market, while at the same time maintaining a highly updated portfolio? No, it is impossible. Of course, high intensity will lead to a higher error threshold for the investor, however, in the short-term period, the significance of the effect of cognitive deviations on the investor's activities will be minimal. As a result, an active manager will have almost the same financial result and knowledge of his own mistakes, which does not have a financial dimension. Such a disposition, as mentioned above, will occur under the assumption that the activity of portfolio management will not decrease.

On the other hand, the strategy of holding a portfolio for a long time, conservatism in managing its securities in the markets of different countries is also quite common, especially in the USA rather than Russia, where the percentage of passive and active portfolio management is both qualitative and quantitative different. Quite often, investors buy a package of securities, best in their characteristics at a certain point, and then simply receive their dividends, coupon payments, and so on, without making changes in the portfolio even when the securities sharply lose in price, or a scandal is associated with the issuer In any case, a situation arises when the value of the securities, the size of the cash flow from the securities in the portfolio decreases. But this is also a case of investor psychology in the market due to its cognitive deviations. And this is not a question of choosing the most profitable tool and managing your portfolio, but a matter of selecting the option of investing temporarily free funds.

As a result, not all investors find it possible, or advantageous, to use research in cognitive finance for portfolio management. Many estimate the cost of a more detailed and meticulous approach to investing higher than the profits from such behaviour in the market. Accordingly, it is not always, from the investor's point of view, to spend time studying a large number of works and publications, while it does not bring tangible, visible improvement in the financial result.

It was noted above that it would take a long time for an individual investor to adapt his breeding investment activity following the experience of financial psychology research. The time lost to re-profiling its activities may be reflected in the omission of the benefits from any transaction.

For a financial market participant, such as a company, or a bank, this is generally not applicable and unacceptable. Even if the participant decides to revise the principles of his activity, then it will cost a lot of time, money, you may have to update the staff of the units responsible for risk analysis and investment decisions. At this time, the participant will lose the competitive advantages associated with the reorganisation, and it is unlikely that the activity of such a participant in the 'noise' market will lead to something good, since the findings, and, accordingly, when focusing on the fundamental and noise information can be completely different. In the short run, the company will almost certainly experience problems with the selection of securities; for this, it will be necessary to form a particular selection policy.

In a real market, to obtain a positive financial result, it is necessary to minimise the role of experience, retrospective data, partnership agreements and other factors on the choice of the investment object. The assessment should be carried out not only by spot (current) indicators but also take into account prospects. In general, when choosing an investment object, the mathematical-analytical approach should prevail. If the investor's cognitive deviation is a fact, then the prevention of the influence of these deviations on the investor's activities is the mathematisa- 
tion of processes, the use of various mathematical models that are part of different software, to which many market participants have access. Again, here it is worth noting the difference between the USA and Russian markets in this nuance. Since the share of investors in the United States is different both in its large number as compared to Russia and in their more profound differentiation among different segments of the population, it turns out that in any case, investors who do not use additional software for analysis and choosing the desired tool, it turns out that there are more such participants in the USA than in Russia. From the Russian market, this statement is supported by the fact that due to the youth of the domestic market, individual investments are made primarily by employees of companies associated with the stock market. It turns out that despite this quantitative limitation, local investors have better access in terms of percentage to the means of mathematical analysis than their foreign counterparts. Accordingly, their potential ability to choose an instrument is higher, relying on its fundamental advantages, rather than on the noise information that wraps it. This opportunity always has a positive impact on the final result of the investor, since even a loss on the instrument will be determined at the macro level, fundamentally, and the responsibility for it will rest with the investor, who in time adopted an appropriate strategy that minimises potential losses.

\section{Conclusion}

During half a century history of behavioural finance it has occupied an important place in financial and economics science. Hundreds of empirical and theoretical studies that have identified systematised and described in detail all sorts of manifestations of irrationality when making decisions have proved the right to the existence of a behavioural approach to the analysis of financial activity that is impossible to ignore. Behavioural finance ideally fit into the already existing concept of financial space, revealing errors and irrationality.

Most modern capital market theories are based on the so-called concept of homo economicus (rationality of economic agents), which imposes certain evident and hidden limitations on the practical side of their implementation.

Studies and research in the field of behavioural economics and finance continue to appear every year, the mathematical base of the approach is getting stronger, there are more and more features, and patterns of influence of the individuality and personality of a specific market participant on the financial decision-making process are identified. The main question in this regard is how long will last the further development of the behavioural approach? Will this development ever be reflected in a more or less significant change in the current algorithm for making final decisions? If the development of behavioural finance continues, then, most likely, at some point, theorists and practitioners of the financial world will need to integrate cognitive finance into their activities in some way, to supplement primary educational literature with behavioural finance.

The generally accepted rational model of stock markets describes not how investors make decisions in reality, but how they should do it. That is the hypothesis of an effectively functioning market abstracted from the personal characteristics of the participants in this market and the psychology of crowd behaviour. In contrast to this point of view, a different perspective on the behaviour of investors prevails in cognitive (behavioural) psychology. It is believed that the process of human decision-making is directly influenced by subconscious factors. Among them are such as mental models (heuristics), emotions, crowd influence, etc.

The theory of behavioural finance has proven and postulated that in the process of forming their future expectations (that is, the market vision), market participants often resort to not exact mathematical calculations and independent analysis of available information but use the so-called rule of thumb or heuristics, that is, simplified solution strategies complex problems with limited information. Such behaviour in the financial and economic markets in some situations may be justified and even necessary. However, in most cases it leads to preconceived future expectations and irrationality of actions.

Not all economists have abandoned their commitment to efficient market theory. But the behavioural approach is now taken seriously. On many issues, the dispute between rational and behavioural has been central to publications on financial economics for more than two decades. Focusing on the data is what makes this debate continue to be valid and productive.

Most economic theories do not proceed from empirical observations; instead, they are based on 
axioms of rational choice, regardless of whether or not these axioms have any relation to what we observe in our daily life. The theory of rational behaviour cannot proceed from empirical data because entirely rational people do not exist.

The combination of facts that are difficult or impossible to reduce to the theory of an effective market, behavioural research - all this contributed to the fact that the field of finance has become an area in which the statements about the invisible hand have undergone a severe review. Financial markets as an area of research are an indication of how a data-based economy can lead to the development of a new theory. The discovery begins with the detection of anomalies. It is impossible to call the completed work on the formation of a new version of finance, based on empirical data, but it is rapidly developing.

However, the principles of behavioural economics and finance can be applied with advantage now.

In a rational world, investor makes financial decision to maximise their risk-return trade-off. They have all the information they need on estimated return and risk, and they make their choices according to this information. In traditional theories of financial investment decisions are based on the assumption that investors act rationally. It means that their behaviour is rational - so they earn returns on the money they put in stock markets. It is essential for investors to have rational behavioural patterns to become successful in the stock market. Rational behaviour is also required to be financially successful and to overcome tendencies.

The modern theory of investors' decisionmaking suggests that investors do not always act rationally while making an investment decision. They deal with several cognitive and psychological errors. These errors are called behavioural biases and are there in many ways.

Thus, summing up, it is worth to say that today, it is simply impossible to deny the existence of a clear relationship between the price movements of the markets and the psychology of their participants. Only by taking into account and comprehensively studying the peculiarities of the behaviour of people as the leading market participants, can we build any kind of holistic and really functioning models of financial decision-making.

People will remain people after thousands of years, so the study of human nature and human behaviour now is of paramount importance and is, in fact, the formation of a kind of foundation for the further construction of the building of behavioural science.

\section{References}

Acharya, V. V., \& Lambrecht, B. M. (2015). A Theory of Income Smoothing When Insiders Know More Than Outsiders. The Review of Financial Studies, 28(9), 2534-2574.

Andersen, S., Ertaç, S., Gneezy, U., Hoffman, M., \& List, J. (2011). Stakes Matter in Ultimatum Games. American Economic Review, 101(7), 3427-3439.

Bailey, M., Cao, R., Kuchler, T., \& Stroebel, J. (2017). The Economic Effects of Social Networks: Evidence from the Housing Market. Journal of Political Economy, forthcoming.

Baker, M., Mendel, B., \& Wurgler, J. (2016). Dividends as Reference Points: A Behavioural Signaling Approach. The Review of Financial Studies, 29(3), 697-738.

Barber, B., \& Odean, T. (2000). Trading is hazardous to your wealth: the common stock investment performance of individual investors. The Journal of Finance, 2(LV), 773-806.

Barr, N. (2012). Economics of the Welfare State. 5th ed. Oxford University Press.

Basu, S. (1983). The relationship between earnings' yield, market value and return for NYSE common stocks. Journal of Financial Economics, 12(1), 129-156.

Bell, A. M., Chetty, R., Jaravel X., Petkova, N., \& Van Reenen, J. (2017). Who Becomes an Inventor in America? The Importance of Exposure to Innovation. NBER Working Paper 24062.

Berk, J., Stanton, R., \& Zechner, J. (2008). Human Capital, Bankruptcy and Capital Structure. SSRN Electronic Journal.

Bloom, N., \& Van Reenen, J. (2007). Measuring and Explaining Management Practices across Firms and Countries. The Quarterly Journal of Economics, 122(4), 1351-1408.

Bogle, J. (2005). The Mutual Fund Industry 60 Years Later: For Better or Worse? Financial Analysts Journal, 61 (1), p. 37. Available at: http://johncbogle.com/wordpress/wp-content/uploads/2010/04/FAJ-Better-or-Worse-60th-anniv.pdf. Accessed 12 March 2019.

Buchanan, D., \& Huczynski, A. (2017). Organizational behaviour. Harlow: Pearson. 
Camerer Colin F. (2001). Behavioural Game Theory: Thinking, Learning, and Teaching. California Institute of Technology. Pasadena, CA.

Cfosurvey.org. (2019). Duke CFO Global Business Outlook. Available at: https://www.cfosurvey.org/.

Chernyavsky, A. D. (2014). Rationality and irrationality in economics. Internet-journal Naukovedenie, 4(23).

Chuvakhin, N. (1960). Efficient Market Hypothesis and Behavioural Finance - Is A Compromise In Sight? Retrieved from http://ncbase.com/papers/EMH-BF.pdf

Cortes, K., Duchin, R., \& Sosyura, D. (2016). Clouded Judgment: The Role of Sentiment in Credit Origination. The Journal of Financial Economics, 121(2), 392-413.

Drkwresearch.com. (2019). Available at: https://www.drkwresearch.com.

Edwards, W. (1968). Book Review: European Behavioural Decision Theory, as SPUDM-14 displayed It. CONTRIBUTIONS TO DECISION MAKING: I. Jean-Paul Caverni, Maya Bar-Hillel, F. Hutton Barron, \& Helmut Jungermann, eds. Amsterdam: Elsevier Science. Journal of Behavioural Decision Making, 9(4), 301-303.

Gagarina, M., \& Goroshnikova, T. (2018). Psychological Factors of Multiple Debt Repayment Strategies. Review of Business and Economics Studies, 6(3), 57-64.

George, S., Sheynin, J., Gonzalez, R., Liberzon, I., \& Abelson, J. (2017). Decision-Making under Risk in Obsessive-Compulsive Disorder and Anxiety: A Cumulative Prospect Theory Model. Biological Psychiatry, 81(10), p. S 127.

Graham, B. (1976). A Conversation with Benjamin Graham. Financial Analysts Journal, 32(5), 20-23.

Graham, J., Harvey, C., \& Rajgopal, S. (2004). The Economic Implications of Corporate Financial Reporting. SSRN Electronic Journal, 14-15. Available at: https://faculty.fuqua.duke.edu/ charvey/Research/Published_Papers/P89The_ economic_implications.pdf. Accessed 9 May 2019.

Guney, Y., \& Iqbal-Hussain, H. (2007). Capital Structure and Market Timing in the UK. Retrieved from https://www.cass. city.ac.uk/_data/assets/pdf_file/0006/56373/2A_Guney.pdf

Heaton, J. B. (2002). Managerial Optimism and Corporate Finance. Financial Management, 2(31), 33-45.

Henrich Joseph et al. (2004). Foundations of Human Sociality. New York: Oxford University Press.

Kahneman, D., \& Tversky, A. (1979). Prospect Theory: An Analysis of Decision under Risk. Econometrica, 2(47), 263-292.

Kahneman, D., Diener, E., \& Schwarz, N. (2003). Well-being. New York: Russell Sage Foundation.

Kahneman, D., Slovic, P., \& Tversky, A. (1999). Judgement under uncertainty. Cambridge: Cambridge University Press.

Klyuev, V. (2008). What Goes Up Must Come Down? House Price Dynamics in the United States. IMF Working Papers WP/08/187.

Kumar, A. (2009). Who Gambles in the Stock Market? The Journal of Finance, 64(4), 1889-1933.

Ma, Y., Sraer, D., \& Thesmar, D. (2018). The Aggregate Cost of Systematic Forecast Errors. Working Paper. Retrieved from https://pdfs.semanticscholar.org/22b6/5ca4b77966600b4b29496ab25aace46f97b8.pdf?_ ga=2.175599650.1690134518.1568984329-1623766573.1511244473.

Malmendier, U., Nagel, S., \& Yan, Z. (2017). The Making of Hawks and Doves: Inflation Experiences on the FOMC. Working Paper. Retrieved from https://pdfs.semanticscholar.org/0981/5cd5805bb26f8b368d86d5d23fcfaf906680.pdf

Morewedge, C., Krishnamurti, T., \& Ariely, D. (2014). Focused on fairness: Alcohol intoxication increases the costly rejection of inequitable rewards. Journal of Experimental Social Psychology, 50, 15-20.

Pouget, S., J. Sauvagnat, and S. Villeneuve (2017). A Mind Is a Terrible Thing to Change: Confirmatory Bias in Financial Markets. The Review of Financial Studies 30 (6), 2066-2109.

Russo, J. Edward, \& Schoemaker, Paul J.H. (1989) Decision traps: Ten barriers to brilliant decision making and how to overcome them. New York: Doubleday.

Sanfey, A. (2003). The Neural Basis of Economic Decision-Making in the Ultimatum Game. Science, 300 (5626), 17551758.

Schmidt, B. (2015). Costs and Benefits of Friendly Boards During Mergers and Acquisitions. The Journal of Financial Economics 117(2), 424-447.

Schneider, C., \& Spalt, O. G. (2016). Conglomerate Investment, Skewness, and the CEO Long- Shot Bias. The Journal of Finance 71(2), 635-672.

Schoar, A., \& Zuo, L. (2017). Shaped by Booms and Busts: How the Economy Impacts CEO Careers and Management Styles. The Review of Financial Studies 30(5), 1425-1456.

Shiller, R. (1980). The Use of Volatility Measures in Assessing Market Efficiency. Cambridge, Mass.: National Bureau of Economic Research. NBER Working Paper No 565. 
Shiller Robert J. Home Page. Available at: http://www.econ.yale.edu/ shiller/.

Shleifer, A. (2000). Inefficient Markets: An Introduction to Behavioural Finance. Oxford University Press UK. Simon H.A. (1955). A Behavioural Model of Rational Choice. The Quarterly Journal of Economics, 1(69), 99-118.

Slovic, P. (1991). Problems of Policy Implementation in Distributed Decision Systems. In R. Weissinger-Baylon \& J. March, eds. Political-military decision making. New York: Pitman. Retrieved from https://scholarsbank.uoregon. edu/xmlui/bitstream/handle/1794/20633/229.pdf?sequence=1 \&isAllowed=y.

Sullivan, K. (1997). Corporate managers' risky behaviour: risk taking or avoiding? Journal of Financial and Strategic Decisions, 10(3), 63-74.

Shyam-Sunder, L., \& Myers, Stewart C. (1999). Testing static tradeoff against pecking order models of capital structure. Journal of Financial Economics, 2(51), 1999, 219-244.

Taleb Nassim. (2005). What Do We Know - The Scandal of Prediction. Available at http://web.archive.org/ web/20130729205852id_http:/itc.conversationsnetwork.org/shows/detail786.html

Thaler, R. (1985). Mental Accounting and Consumer Choice. Marketing Science 4(3), 199-214.

Thaler, R. H. (1988). Anomalies: The Winner's Curse. The Journal of Economic Perspectives 2(1), 191-202.

Thaler, R. H. (1999). Mental Accounting Matters. Journal of Behavioural Decision Making 12(3), 183-206.

Thaler, R. H. (2015). Misbehaving: The making of behavioural economics. New York, NY: W W Norton \& Co.

Thaler, R. H., \& Sunstein, C. R. (2003). Market Efficiency and Rationality: The Peculiar Case of Baseball. Michigan Law Review 102(6), 1390-1403.

Torngren, G., \& Montgomery, H. (2004). Worse Than Chance? Performance and Confidence Among Professionals and Laypeople in the Stock Market. Journal of Behavioural Finance, 5(3), 148-153.

Towards Data Science. (2019). The house always wins: Monte Carlo Simulation. Available at: https://towardsdatascience.com/the-house-always-wins-monte-carlo-simulation-eb82787da2a3.

Tversky, A., \& Kahneman, D. (1992). Advances in prospect theory: Cumulative representation of uncertainty. Journal of Risk and Uncertainty, 5(4), 297-323.

Warusawitharana, M. and T.M. Whited (2016). Equity Market Misvaluation, Financing, and Investment. The Review of Financial Studies 29(3), 603-654.

West, K., \& Shiller, R. (1991). Market Volatility. Economica, 58(230), 269.

Теория и практика поведенческой экономики в процессе принятия финансовых решений

Мария Розина

Магистр экономических наук

Международный финансовый факультет,

Департамент мировой экономики и мировых финансов,

Финансовый университет, Москва, Россия

Научный руководитель: Горошникова Татьяна Аркадьевна, к.т.н., Международный финансовый факультет, Департамент мировой экономики и мировых финансов, Финансовый университет, Москва, Россия

Аннотация. В статье рассмотрены вопросы, связанные с изучением поведенческих факторов при принятии финансовых решений. Цель исследования - проверка гипотезы о том, что участники рынка принимают финансовые решения, основываясь на своем опыте, интуиции, стереотипах, иллюзиях, эмоциях, а не только на критериях финансовой выгоды и рациональных предположениях. Исследованы и обобщены поведенческие механизмы и основные ошибки инвесторов и менеджеров при принятии финансовых решений на основе классической экономической теории. Приведены конкретные примеры реализации финансовых решений с использованием математических моделей. Практическая значимость данного исследования - выявление ошибок в применении классической экономической теории, возможности и способы их устранения. В качестве основного инструмента принятия финансовых решений представлена эффективная поведенческая модель, позволяющая избегать негативных последствий.

Ключевые слова: поведенческая экономика; принятие решений; инвестор; homo economicus; рациональные решения; иррациональность 